\title{
Feedstock recycling of waste polymeric material
}

\author{
Guido Grause $\cdot$ Alfons Buekens $\cdot$ Yusaku Sakata \\ Akitsugu Okuwaki $\cdot$ Toshiaki Yoshioka
}

Received: 28 September 2011 / Accepted: 13 October 2011/Published online: 1 November 2011

(C) The Author(s) 2011. This article is published with open access at Springerlink.com

\begin{abstract}
The first International Symposium on Feedstock Recycling of Polymeric Materials (ISFR) was hosted in 1999 in Sendai, Japan. Since then, the ISFR has been held five times in different places in Asia and Europe. Each of these conferences focused on special issues covered by the Journal of Material Cycles and Waste Management. The topics included thermal processes with and without catalysts, wet processes in various solvents, the dehydrochlorination of PVC, mechanical recycling and separation techniques, as well as the treatment of biomaterials. This review is a compilation of the most interesting and important developments discussed at the ISFR during the last decade.
\end{abstract}

Keywords ISFR - Thermal processes - Dehalogenation · Solvolysis $\cdot$ Mechanical recycling

Dr. Buekens is Prof. Emeritus, Vrije Universiteit Brussel, Brussels, Belgium.

G. Grause · A. Okuwaki · T. Yoshioka ( $₫)$

Graduate School of Environmental Studies,

Tohoku University, Sendai, Japan

e-mail: yoshioka@env.che.tohoku.ac.jp

A. Buekens

State Key Laboratory of Energy Clean Utilization, Institute for Thermal Power Engineering,

Zhejiang University, Hangzhou, China

Y. Sakata

Department of Applied Chemistry, Faculty of Engineering,

Okayama University, Okayama, Japan

\section{Introduction}

We are eagerly anticipating the 6th International Symposium on Feedstock Recycling of Polymeric Materials (ISFR), which will be held this year in Toledo, Spain, from the 5 to 7 October. More than a decade has past since the first ISFR meeting in Sendai, Japan, in 1999 (Table 1). Since the symposium has consistently had its focus on special issues published in the Journal of Material Cycles and Waste Management, it has provided us with the opportunity to review the major challenges and perspectives of the day, reflecting on the special issues and related publications from other journals.

One issue consistently given a lot of attention over the years is the dehalogenation of waste plastics, which can be divided into two large fractions, municipal waste and waste electric and electronic equipment (WEEE). Notably, about $30 \%$ of the first ISFR was dedicated to the dehydrochlorination of PVC [1], and it has remained an important topic during all the conferences since then. The other topics covered in the first ISFR included degradative extrusion, depolymerization, solvolytical processes, and petrochemical processes. While the topic of degradative extrusion has lost relevance, other topics of interest have come to the forefront. Besides mechanical recycling and life cycle assessments, political and social aspects have been discussed, and they all have gained more attention over the years. In the 5th ISFR in Chengdu (China), the degradation of biomass was added to the program, completing the scope of polymeric materials that can be employed for the recovery of fuels and chemicals.

Over the course of the last 10 years, new processing techniques have been developed and employed in the recycling and degradation of plastics. The dehydrochlorination of poly(vinyl chloride) (PVC) by microwave 
Table 1 ISFR conferences

\begin{tabular}{ll}
\hline Sendai (Japan) & 1999 \\
Ostend (Belgium) & 2002 \\
Karlsruhe (Germany) & 2005 \\
Jeju Island (South & 2007 \\
$\quad$ Korea) & \\
Chengdu (China) & 2009 \\
Toledo (Spain) & 2011 \\
\hline
\end{tabular}

radiation [2, 3], the depolymerization of various polycondensates and adducts [4-6], as well as the dehydrochlorination of PVC [7] in ionic liquids, and the separation of PVC and poly(ethylene terephthalate) (PET) from mixed waste plastics by froth floating after a surface treatment [8] are just a few examples of applications of these innovative techniques.

Another tendency seen over the last decade or thereabouts has been the utilization of waste for the treatment of other sorts of waste. Oyster shells with their high $\mathrm{CaCO}_{3}$ content were employed in the mechanochemical dehydrochlorination of PVC [9], while $\mathrm{HCl}$ derived from the thermal dehydrochlorination of PVC can be used for the volatilization of metals that form volatile chlorides, i.e., $\mathrm{InCl}_{3}$ was recovered from liquid crystal displays [10]. All these results show the possibility to minimize waste by constructing an integrated waste management system.

Therefore, the value of plastic waste should not be assessed only in terms of its valuable metal content (i.e., WEEE) or the fuel or chemicals that can be obtained from its degradation. The inherent specific properties of waste material should also be considered as a source of added value. Here we will outline the progress that has been made over the last 10 years in different fields of feedstock recycling and look at how approaches have changed during this time.

\section{Liquefaction and pyrolysis}

The aim of liquefaction is to yield gas and oil as a source of fuels and chemicals and waxes in the form of chemical compounds. Gasification, on the other hand, will be discussed in a separate section, since the aim of gasification is to yield gases such as hydrogen and carbon monoxide as a source for the production of chemicals or fuels, even though the processes involved are quite similar to those used in pyrolysis. The techniques employed in the production of activated carbon are very similar to those used in gasification. Steam, oxygen, and carbon dioxide are used for the reactive activation of char. Therefore, this process will be discussed together with gasification.
Furthermore, liquefaction can be conducted in the presence or absence of catalysts. While thermal decomposition is characterized by the radical fission of the polymer backbone, in the presence of a catalyst, charges are frequently involved that reduce the reaction temperature and alter the product distribution. Therefore, both processes are dealt with in separate sections.

\section{Thermal decomposition}

The efficiency of a recycling process depends strongly on the composition of the waste material that can be provided. A good feedstock consisting of one component allows the production of a defined product during its thermal degradation. In many cases, monomers can be recovered in high yields, as has been shown for poly(methyl methacrylate), polystyrene, poly(tetrafluoro ethylene), and some other polymers. Unfortunately, feedstock like this is rare, and, in general, obtained from fabrication reject. Also, even in these productive cases, additives tend to reduce the quality of the resulting product. However, the reality in waste plastic recycling is mixed waste, the kind of waste we find in the plastic fraction of municipal solid waste (MSW): it has a high content of polyolefins [high-density polyethylene (HDPE), low-density polyethylene (LDPE), polypropylene (PP)], polystyrene (PS), and a smaller amount of PVC and PET in changing compositions. This plastic fraction also contains other foreign materials like paper, metal, and glass, which may also have an impact on the product distribution. Generally, monomer recovery from a mixed plastic fraction is not feasible economically because of the high costs of product separation. Therefore, mixed plastics are commonly considered as a source of oils and gas, both of which can be used as fuels [11].

Several points have to be taken into consideration if pyrolysis is chosen as the waste treatment method. First of all, every kind of plastic has its own degradation behavior. There is no golden solution that provides an optimum for every plastic in a mixture or can be applied to various single plastics using the same process at the same conditions. The optimal temperature for a certain plastic might result in insufficient degradation of another plastic. It might also cause the degradation of a desired product or result in a secondary reaction between degradation products. The second point is that some plastics have a negative effect on the technical process or the product quality. PVC releases corrosive $\mathrm{HCl}$ gas during the degradation process, which does harm to the treatment facility. Due to the corrosive character of chloride, it also has to be limited in the product oil if it has to be considered as a fuel. The degradation of PET results in organic acids, which also are corrosive in character. Furthermore, the high sublimation point of terephthalic acid, at around $400^{\circ} \mathrm{C}$, leads to blockages in 
pipes. PET is also known to cause defluidization in fluidized bed reactors because of the formation of residual material.

There are various types of reactors in use for the pyrolysis of waste plastics. Fluidized bed reactors and rotary kilns are the most common solutions. Batch or continuous stirred tank reactors are characterized by insufficient heat transfer, which results in the formation of char. Degradative extrusion is mainly used in the dehydrochlorination of PVC. It should be noted that at the time of the first ISFR, molten metal baths were already considered obsolete technology because of the formation of toxic organometal compounds and the superior heat and mass transport properties of other reactor types [11].

Many contributors used the fluidized bed reactor as a technical solution for plastic pyrolysis [12, 13]. Kodera et al. [14] proposed an extruder-like moving bed reactor, using sand as a medium for heat transfer. Vasile et al. [15] used a two-step process for the degradation of plastics and thermoset fractions from used computers consisting of an extruder for the degradation of the material. The attached fixed bed reactor contained a catalyst for the cracking of the wax-like pyrolysis products. Laboratory-scale experiments were also conducted in autoclaves [16, 17] and quartz tube reactors [18-20]. Yasuda et al. [21] used a batch reactor especially equipped with a gas sampler for the collection of highly concentrated product gas.

When choosing an appropriate reactor type, two main factors have to be considered-heat and mass transfer. Due to the low heat conductivity of plastic materials, heat transport is very slow and heat distribution is inhomogeneous in the plastic melt. When small sample sizes of less than $1 \mathrm{~g}$ are used, fixed bed quartz tube reactors might be used. At larger sample sizes, the heat transfer has to be improved. This is usually achieved by moving the melt by extruders or rotary kiln, or in fluidized bed reactors. In fluidized and moving bed reactors, additional heat transfer media are employed. Due to the high viscosity of polymer melts, the shear forces also have an impact on the cracking behavior. Reduced diffusion increases the possibility of secondary reactions that can alter the product distribution.

The focus on the pyrolysis of polyolefins over the years can be attributed to the high content of polyolefins in the MSW fraction. The pyrolysis of polyolefins does not lead solely to momomers even when ethane and propene can be found in the product composition, but depending on the temperature, wax, aliphatic oil, aromatic oil, and gas are obtained. Low temperature pyrolysis at about $450^{\circ} \mathrm{C}$ results in waxes. Higher temperatures result in a higher cracking strength and the production of aliphatic oils and gases. Temperatures of more than $600^{\circ} \mathrm{C}$ result in the formation of aromatics from gaseous olefins by Diels-Alder reactions.
Kodera et al. [14] proposed a moving bed reactor for the pyrolysis of polyolefins. It consisted of a screw feeder in which a mixture of sand and PP was pyrolyzed between 500 and $700^{\circ} \mathrm{C}$. The result was a mixture of hydrocarbons, and with rising temperature, the oil yield decreased and the gas yield increased. Murata et al. [22] found that product distribution derived from the pyrolysis of PE could be controlled with pressure because of the fission of the polymer backbone and the subsequent increase in the formation of double bonds. Williams and Williams [23] found when they heated HDPE, LDPE, and PP at a constant heating rate of $25 \mathrm{~K} \mathrm{~min}^{-1}$ up to $700^{\circ} \mathrm{C}$ that each of these plastics released about $80 \mathrm{wt} \%$ of wax and oil as the main product fraction. With the addition of PS, there were higher gas yields and a more significant reduction of the liquid fraction than the predicted composition, which led to the assumption that PS has a positive effect on the polyolefin degradation. Sugano et al. [16] investigated the effect of hydrothermal treatment on the liquefaction of mixed plastics. They found that pretreated PS and HDPE were degraded between 300 and $400^{\circ} \mathrm{C}$, yielding more oil than untreated samples. Optimal conditions were achieved at $350^{\circ} \mathrm{C}$ at a reaction time of $60 \mathrm{~min}$. Karayildirim et al. [24] found that the addition of PE/PVC to heavy vacuum gas oil (HVGO) had a positive effect on the cracking of HVGO. At a relatively low temperature of $400^{\circ} \mathrm{C}$ without using a catalyst, HVGO and polymers were sufficiently degraded. In the first step of their setup, Hajekova and Bajus [25] pyrolyzed LDPE and PP at $450^{\circ} \mathrm{C}$ in a batch reactor. The resulting wax was then copyrolyzed with naphtha at temperatures between 740 and $820^{\circ} \mathrm{C}$. No significant difference between the individual cracking of naphtha and the copyrolysis with the polyolefin wax was observed. These results show that polymers and polymer-derived waxes can be added as feedstocks to petrochemical processes.

A technical example of the development of a feedstock recycling process is the Sapporo waste plastic liquefaction plant (SPR), which has been well documented during the ISFR conferences [26-29]. The SPR (shown in Fig. 1), which was designed as a liquefaction facility for dehydrochlorinated mixed waste plastics, started operation in 2000. During pretreatment, foreign materials (glass, metal, etc.) and water were removed. The remaining plastic materials were pelletized and dehydrochlorinated at temperatures between 300 and $330^{\circ} \mathrm{C}$. The evolving gas was incinerated; $\mathrm{HCl}$ was absorbed in the water, which was then sold as hydrochloric acid. The dehydrochlorinated polymer melt was pyrolyzed at 400 to $450^{\circ} \mathrm{C}$ for $10 \mathrm{~h}$ and the evolved gases were distilled, resulting in light $\left(120^{\circ} \mathrm{C}\right)$, medium $\left(200^{\circ} \mathrm{C}\right)$, and heavy oil $\left(280^{\circ} \mathrm{C}\right)$. The residue was pelletized and sold as solid fuel.

The feedstock consists of plastic waste from MSW collected all over Hokkaido. This plastic fraction consisted 
Fig. 1 Functional outline of the Sapporo Plastics Recycling (SPR) Co., Ltd., plastics liquefaction process. $H x$ heat exchanger [27]

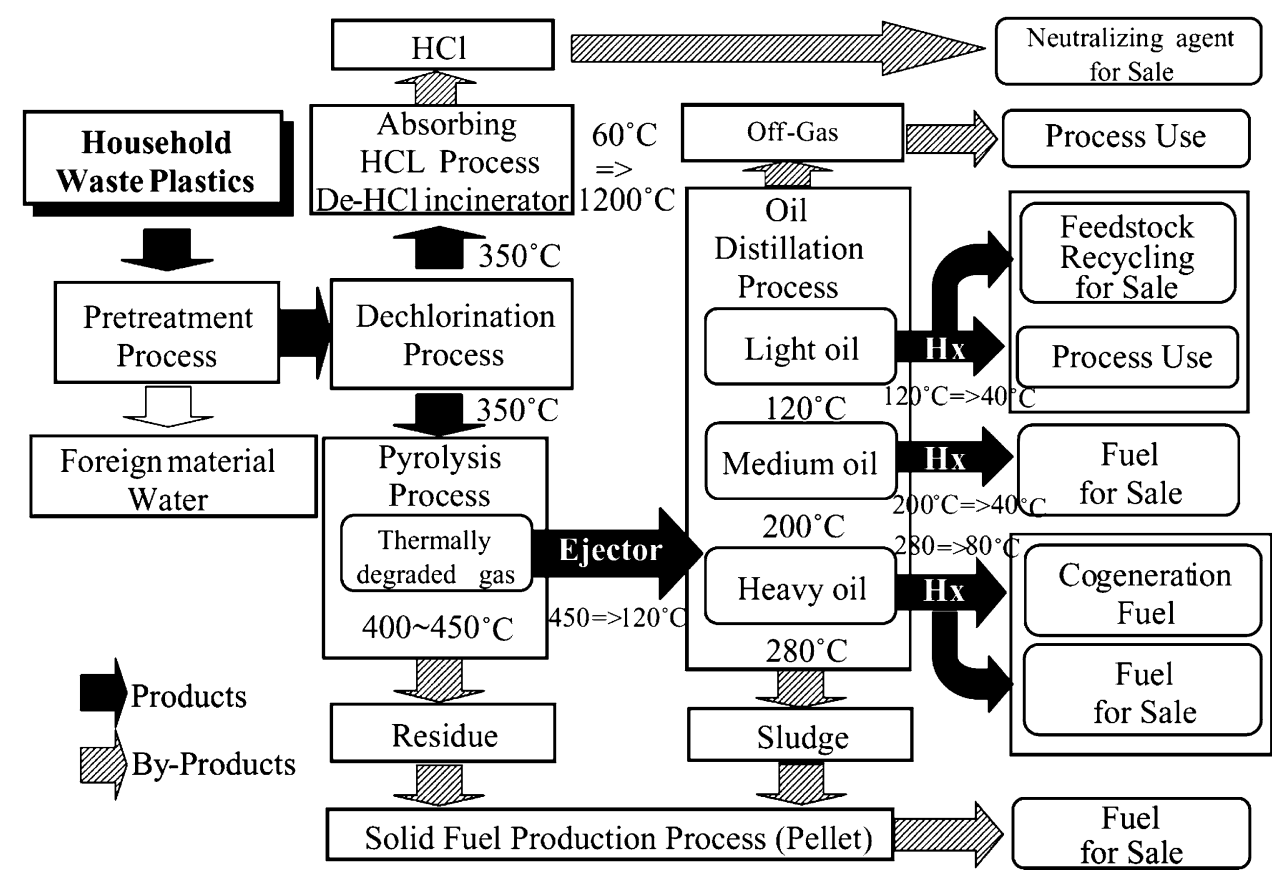

of 60 to $90 \mathrm{wt} \%$ of PE, PP, and PS, up to $6 \mathrm{wt} \%$ of PVC, and up to $15 \mathrm{wt} \%$ of PET. As can be seen, a liquefaction plant using MSW has to be able to treat feedstock with compositions that can change radically from one time to the next. Problems were encountered at first due to the presence of PET, which caused clogging and corrosion. While heating up, there was a problem with the evolution of organic acids, mainly benzoic acid and terephthalic acid, in the temperature range between 170 and $250^{\circ} \mathrm{C}$. As a countermeasure, hydrated lime $\left(\mathrm{Ca}(\mathrm{OH})_{2}\right)$ was added, and organic acids were decarboxylized. The amount of processed plastic waste at the SPR increased from 2,800 $\mathrm{t}$ in 2000 to its nominal capacity of $14,800 \mathrm{t}$ in 2009 .

Kato et al. [30] investigated the possibility of using waste plastics in coke ovens. It was found that plastic can be used for large-scale coke production. Besides coke, large amounts of gas and oil were obtained without affecting the coke strength.

The pyrolysis of poly(methyl methacrylate (PMMA)) is a good example of possible monomer recovery by thermal depolymerization. The reaction proceeds at temperatures above $400^{\circ} \mathrm{C}$ with high yields. Since methylmethacrylate (MMA) is probably the most expensive monomer used in mass-produced plastic, a recovery method that used a molten lead bath pyrolysis system had already been established. Even though lead was later replaced by tin, both metals form toxic metalorgano compounds that harm both the environment and human health. Today fluidized bed reactors are used for the recovery of MMA. Due to their good heat and mass transfer properties, this technique is much better than the molten metal baths used in the past.
Smolders and Baeyens [31] compared the kinetics of the PMMA depolymerization in a molten lead bath and a fluidized bed reactor. Regardless of the metal bath temperature, they observed an MMA yield of $87 \%$. An MMA yield of more than $98 \%$ was observed between 450 and $490^{\circ} \mathrm{C}$. Slightly lower MMA yields were found by Kang et al. [32]. Virgin PMMA resulted in MMA yields of 96.7 and $95.0 \%$ at 440 and $470^{\circ} \mathrm{C}$, respectively, when a fluidized bed was used. MMA yields were slightly lower when real waste materials were depolymerized. The purity of MMA could be improved from about $95 \mathrm{wt} \%$ in the pyrolysis oil to $99.8 \mathrm{wt} \%$ by distillation [33].

Using the Osawa method, Kim et al. [34] found an activation energy of $214 \mathrm{~kJ} \mathrm{~mol}^{-1}$ for a first order depolymerization of PMMA. Activation energies between 102 and $331 \mathrm{~kJ} \mathrm{~mol}^{-1}$ were found by other methods [32]. The MMA yield depended more on the gas residence time than on the temperature, showing the importance of quickly removing produced gases from the hot reactor zone. At low temperatures, the reaction was kinetically controlled, while at higher temperatures, the reaction was limited by the heat transfer [31].

\section{Catalytic processes}

The thermal degradation of plastics often results in a product distribution that does not match the requirements. Alkenes from the fission of polyolefins tend to be chemical instable. They are easily oxidized in the presence of atmospheric oxygen, and polymerization leads to the alteration of the oil properties. Polyesters release organic 
acids, which cause corrosion and clogging. Last but not least, the chain length and isomerization degree may not be in the desired proportions. Therefore, the aims of the catalytic processes are many: the hydrogenation of alkenes, the removal of heteroatoms, such as oxygen, nitrogen, and halogens, the reduction of the degradation temperature of the polymer, and the isomerization of products. In order to achieve these aims several classes of catalysts have been developed.

The most prominent group of catalysts is fluidized cracking catalysts (FCC). They were developed for the catalytic cracking of high boiling crude oil fractions in order to increase the output of light oil and to obtain highly branched hydrocarbons. Since polyolefins are chemically very similar to naphtha, a shortcut for enhancing the degradation of polyolefins is to employ FCC catalysts.

Most of these catalysts are zeolites or modified zeolites. Lee et al. [35] used a spent FCC catalyst for the degradation of HDPE/PS mixtures in a stirred semi-batch reactor at $400^{\circ} \mathrm{C}$. More than $85 \mathrm{wt} \%$ of liquid products, parafins, olefins, naphthenes, and aromatics were obtained. Only a small amount of waxes were obtained. Compared with the uncatalyzed reaction, the reaction proceeded much faster. Vasile et al. [36] investigated the effect of H-ZSM5 and the orthophosphoric acid modified catalyst P-ZSM5 on the degradation of a polyolefin-rich mixed plastic fraction in a two-step process. Plastic degradation took place between 450 and $460^{\circ} \mathrm{C}$ with the employment of an extruder. The gases produced were pipelined through a fixed bed filled with the catalyst at temperatures between 420 and $480^{\circ} \mathrm{C}$. The boiling point of the product oil was lower in the presence of a catalyst than in the uncatalyzed reaction. H-ZSM5 catalyzed the formation of isomers, while the use of P-ZSM5 resulted in $\alpha$-alkyl substitution and condensed aromatics. Nishino et al. [37, 38] reported the use of gallium silicate and H-ZSM5 supported gallium oxide for the degradation of polyolefins at temperatures between 450 and $550^{\circ} \mathrm{C}$. Using a stirred batch reactor for the pyrolysis of the polyolefins between 450 and $510^{\circ} \mathrm{C}$ and a fixed bed containing gallium silicate between 550 and $580^{\circ} \mathrm{C}$, highly aromatic oil with a yield between 55 and $68 \mathrm{wt} \%$ was obtained. The use of the H-ZSM5-supported gallium oxide catalyst significantly reduced the molecular weight of the pyrolysis products and resulted in the formation of highly aromatic oil (Fig. 2). Serrano et al. [39, 40] found that H-ZSM5 was more efficient in the cracking of LDPE and LDPE-EVA (ethylene-vinyl acetate copolymer) blends than mesoporous aluminum silicate catalysts (Al-MCM-41 and Al-SBA-15). Pyrolysis at $700^{\circ} \mathrm{C}$ by Py-CG-MS resulted in high yields of light hydrocarbons and some aromatic compounds. The degradation of LDPE-EVA in a batch reactor between 400 and $420^{\circ} \mathrm{C}$ gave mainly $\mathrm{C}_{1}-\mathrm{C}_{5}$ hydrocarbons. Aromatics were a minor product. Acetic acid was released from EVA between 350 and $400^{\circ} \mathrm{C}$. Karagöz et al. [41] compared the catalytic efficiency of H-ZSM5, DHC8, and active carbon supported cobalt in the degradation of municipal waste plastic and HVGO at temperatures between 425 and $450^{\circ} \mathrm{C}$. H-ZSM5 and active
Fig. 2 Chromatograms of the pyrolysate of $\mathrm{LDPE}$ at $500^{\circ} \mathrm{C}$ : a uncatalyzed, $\mathbf{b}$ catalyzed by H-ZSM5 supported gallium oxide containing $4.5 \mathrm{wt} \% \mathrm{Ga}$ (GZ-4.5), and chromatograms of the pyrolysate of refused plastic fuel at $500^{\circ} \mathrm{C}$ : c uncatalyzed, d GZ-4.5 catalyzed [38]
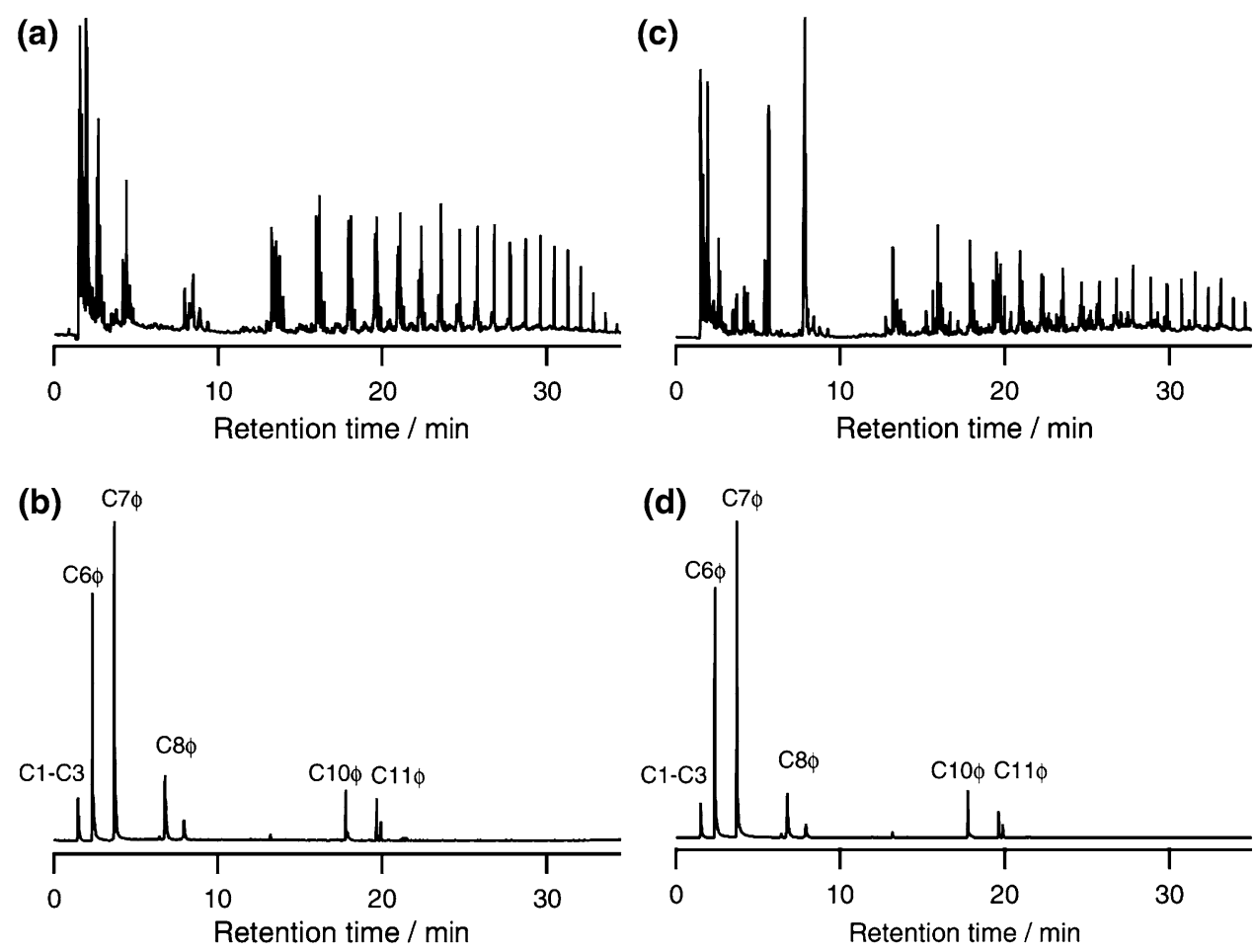
carbon supported cobalt showed comparable catalytic activities with high oil yields in the lower temperature range and an increasing gas production at higher temperatures, while DHC8 produced the highest oil yields at the highest temperature of $450^{\circ} \mathrm{C}$.

Serrano et al. [39] showed that at temperatures as low as $420^{\circ} \mathrm{C}$, aluminum silicate catalysts were not performing as well as zeolites. Nevertheless, these materials allow us to observe catalytic activity and can be used as supporting materials for other catalytic active metal ions. A pure silica-alumina cracking catalyst was used by Wallis et al. [42] for the degradation of HDPE in a reactive extruder. They obtained high yields of $\mathrm{C}_{5}$-hydrocarbons. A kinetic model was proposed that was capable of describing the results at a low temperature of $425^{\circ} \mathrm{C}$. The model was less accurate at higher temperatures. Na et al. [43] synthezised silica-alumina catalyst from fly ash and used it for the pyrolysis of LDPE during thermogravimetric analysis. The performance of the fly ash-derived catalyst was similar to that of commercially available catalysts. Vasile et al. [44] used the commercial catalyst DHC-8 for the hydrogenation of thermosets derived from computers. Since thermosets contain high amounts of heteroatoms and also flame retardants, the hydrogenation removed toxic compounds from the product oil. It also improved the chemical stability of the oil because of the removal of olefins. The hydrogenation process resulted in an aromatic content of the oil of $60-89 \mathrm{wt} \%$, making this oil suitable as a feedstock for the recovery of aromatic compounds.

Kaminsky and Zorriqueta [45] used Ziegler-Natta catalysts for the degradation of PP. Ziegler-Natta catalysts are frequently used for the polymerization of polyolefins. Therefore, this class of catalysts was also thought to be efficient in the degradation of polymers. It was found that the pyrolysis temperature can be reduced by $100 \mathrm{~K}$ in the presence of these catalysts. Also, the possibility of a pyrolysis at $300^{\circ} \mathrm{C}$ was suggested. Sekine and Fujimoto [46] investigated the effect of an activated carbon supported iron catalyst on the degradation of PP in an argon and hydrogen atmosphere between 400 and $420^{\circ} \mathrm{C}$. In the presence of hydrogen, more liquid products were obtained. The amount of residue and the reaction time were reduced (Fig. 3). Yanik et al. [47] investigated the effect of red mud on the pyrolysis of a mixture of $\mathrm{MSW}$ and $\mathrm{HVGO}$ at $430^{\circ} \mathrm{C}$. The catalyst increased the yield of the liquid fraction, which was distributed over a wide range of carbon numbers $\left(\mathrm{C}_{5-}\right.$ $\mathrm{C}_{25}$ ). The highest yield obtained was for $\mathrm{C}_{9}$.

Botas et al. [48] used the olefin-rich fraction of PE pyrolysis to upgrade the oil by Wacker oxidation in order to obtain methylketones. Olefins were oxidized at $80^{\circ} \mathrm{C}$ by tert-butyl hydroperoxide. High selectivity was observed when acetonitrile was used as a solvent.

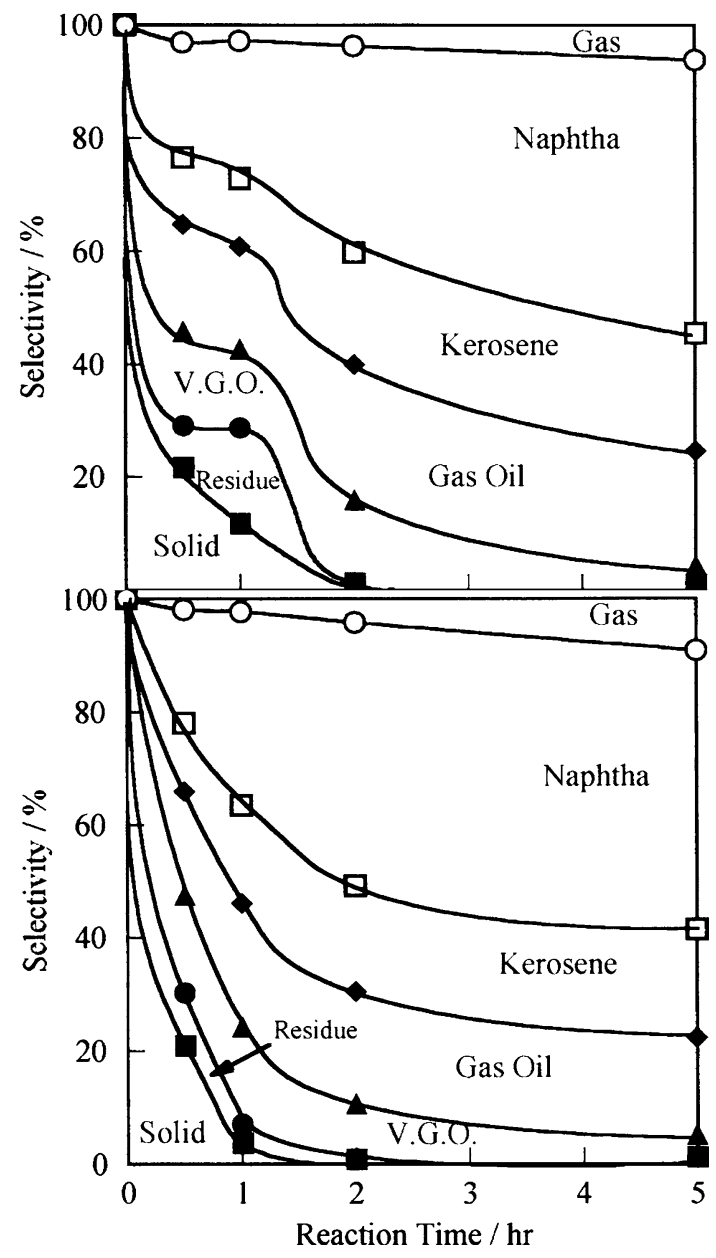

Fig. 3 Effect of reaction time on the product distribution under $\mathbf{a}$ argon and b hydrogen atmosphere. Plastics: polypropylene, $15 \mathrm{~g}$; catalyst, Fe/active carbon $0.45 \mathrm{~g}$; pressure, 4.0 MPa (STP); reaction temperature, $400^{\circ} \mathrm{C}[46]$

Another important problem is the degradation of organic acids derived from PET and other polyesters. Terephthalic acid was especially problematic since its high sublimation temperature of about $400^{\circ} \mathrm{C}$ resulted in the clogging of pipes. Therefore, finding the most appropriate catalysts for the decarboxylation of these acids is a matter of high technical relevance. Chiu and Cheng [49] used $\mathrm{CuCl}_{2}$ to enhance degradation in the temperature range between 350 and $500^{\circ} \mathrm{C}$. PET impregnated with $\mathrm{CuCl}_{2}$ showed the largest weight loss. However, $\mathrm{CuCl}_{2}$ did not change the product distribution. Organic acids remained present in the catalyzed product sample. Due to the presence of chloride, six chlorinated organic products were observed. Obuchi et al. [50] investigated the degradation of PP/PET mixtures using a titania/silica catalyst at $425^{\circ} \mathrm{C}$. The plastic was converted into gas and oil without the formation of solid products. The amount of waxes increased with the PET content of the plastic sample. The liquefaction of PET was attributed to the transfer of hydrogen from PP via Lewis- 
acid sites of the titania/silica catalyst. Yoshioka et al. [51, 52] decarboxylated various polyesters in the presence of $\mathrm{Ca}(\mathrm{OH})_{2}$ between 600 and $800^{\circ} \mathrm{C}$ in a steam atmosphere. It was found that a high $\mathrm{Ca}(\mathrm{OH})_{2} /$ polyester weight ratio of 10:1 at $700^{\circ} \mathrm{C}$ gave the best results. The decarboxylation of PET resulted in benzene rich oil with a purity of $79 \mathrm{wt} \%$ and a benzene yield of $85 \%$. Similar results were obtained for poly(ethylene naphthenate) and poly(butylene terephthalate). It was assumed that the polyester was hydrolyzed during the first step, and the resulting terephthalic acid was decarboxylized when it came into contact with $\mathrm{CaO}$. Grause et al. [53] used hard burnt lime (HBL) as the bed material in a fluidized bed reactor for the decarboxylation of PET degradation products during the pyrolysis of mixed plastics containing PE, PP, PS, and PET at 600 and $700^{\circ} \mathrm{C}$. Compared with quartz sand as the bed material, more gas and less wax were obtained. In the presence of HBL, organic acids were not detected.

Grause et al. [54] found that the hydrolysis of polycarbonate in a steam atmosphere and in the presence of earth alkali metal oxides resulted in high yields of phenols, in which $\mathrm{MgO}$ was more active than $\mathrm{CaO}$. At $300^{\circ} \mathrm{C}$, bisphenol-A (BPA) was the main product, while at $500^{\circ} \mathrm{C}$ the fission of BPA resulted in high yields of phenol and isopropenylphenol.

\section{Gasification}

The aim of gasification is to produce high calorific gases by the partial oxidation of organic feedstocks and coal by steam, oxygen, or carbon dioxide. The conventional feedstocks are fossil fuels. However, because of the need to reduce carbon dioxide emissions, waste plastic materials and biomass are considered appropriate replacement materials. The product gas consists mainly of hydrogen and carbon monoxide, in which hydrogen is of special interest because of the developing hydrogen energy cycle. Activated carbon and nanotubes are also accessible by the gasification processes.

Tsuji et al. [55, 56] proposed a two-step process for the gasification of polyolefins. In the first stage, polyolefins are pyrolyzed at $470^{\circ} \mathrm{C}$ in a melting vessel. The oil yield derived from the first stage reached about $90 \mathrm{wt} \%$, while little coke was produced. In the second stage, the oil was gasified in a steam atmosphere using a tubular reactor at about $800^{\circ} \mathrm{C}$ in the presence of a $\mathrm{Ni}-\mathrm{Al}_{2} \mathrm{O}_{3}$ as the gasification catalyst. Although the plastic-derived oil contained large amounts of high molecular aliphatic and aromatic hydrocarbons, the coking rate was low, and the hydrogen content of the synthesis gas was about 70 vol\%. Similar results were obtained during the steam reforming of waste plastics when a fluidized bed reactor was used instead of a tubular reactor [57]. Tongamp et al. [58] obtained hydrogen gas by ball milling $\mathrm{PE}$ with $\mathrm{Ca}(\mathrm{OH})_{2}$ and $\mathrm{Ni}(\mathrm{OH})_{2}$, and subsequently heating the sample at a heating rate of $20 \mathrm{~K} \mathrm{~min}^{-1}$ to a maximum temperature of $700^{\circ} \mathrm{C}$. During this process, hydrogen was the main gas released. The highest purity of hydrogen gas was observed at a $\mathrm{C} / \mathrm{Ca} / \mathrm{Ni}$ ratio of $6: 14: 1$, with a gas containing 95 vol\% hydrogen and $5 \mathrm{vol} \%$ methane evolving between 400 and $500^{\circ} \mathrm{C}$. Slapak et al. [59] calculated the cost of using a fluidized bed gasification plant to convert 50 kton PVC waste/year into synthesis gas and $\mathrm{HCl}$. The aim was to use the synthesis gas for energy recovery. Half of the chlorine is recovered as pure $\mathrm{HCl}$ gas; the other half is $\mathrm{CaCl}_{2}$ and has to be disposed of. The investment costs were calculated to be 10 million euros, resulting in an expected gate fee of 67 euros with a strong dependence on the $\mathrm{CaCl}_{2}$ disposal costs. Yamamoto et al. [60] proposed a process combining the production of high calorific gases from MSW with the smelting of iron ore. The gas consisted mainly of carbon oxides and hydrogen. Dioxin emissions remained low, while volatile heavy metals were removed with the gas stream, assuring low concentrations of heavy metals in the slag. Kawamoto and Mabuchi [61] investigated the formation of polychlorinated dibenzodioxins (PCDDs) and dibenzofurans (PCDFs) in the fly ash from a gasification process of MSW. PCDDs and PCDFs were formed at the surface of fly ash even in the absence of precursors and at a low carbon content of the fly ash. The highest concentrations were observed in a narrow temperature range at around $350^{\circ} \mathrm{C}$.

Kamo et al. [62] investigated the gasification of dehydrochlorinated PVC and activated carbon in the presence of various hydroxides and carbonates using a batch reactor. The reaction was carried out under relatively mild conditions at temperatures between 560 and $660^{\circ} \mathrm{C}$ and a nitrogen pressure of $3.0 \mathrm{MPa}$. High yields of hydrogen were obtained with $\mathrm{KOH}$ and $\mathrm{NaOH}$ as reactants. The steam gasification of activated carbon in the presence of $\mathrm{Li}_{2} \mathrm{CO}_{3}, \mathrm{Na}_{2} \mathrm{CO}_{3}$, and $\mathrm{K}_{2} \mathrm{CO}_{3}$, respectively, resulted at $700^{\circ} \mathrm{C}$ in the formation of hydrogen and carbon dioxide [63]. The presence of carbonate and an increasing partial pressure of steam accelerated the hydrogen production significantly.

Yasuda et al. [64] gasified a mixture of coal and PE at $800^{\circ} \mathrm{C}$ in a hydrogen atmosphere at a pressure of 7.1 MPa. The gasification of sole PE yielded 90\% methane after $80 \mathrm{~s}$. The mixing of coal and PE enhanced the methane formation, probably because of the compensation of the endothermic heat consumption of the coal hydrogenation by the exothermic heat release of the methane formation from PE. The addition of PE to coal in hydrogasification processes was suggested. Due to the low quality of Korean anthracite coal, Choi et al. [65] 


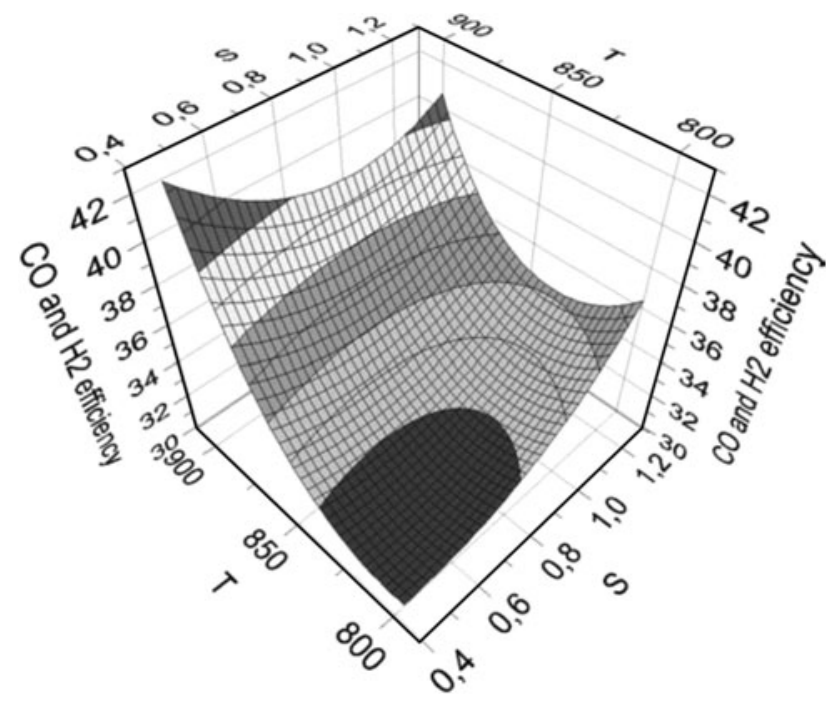

Fig. $4 \mathrm{CO}$ and $\mathrm{H}_{2}$ efficiency as a function of temperature $(T)$ and the amount of steam added to the feed $(S)$ at an equivalence ratio of 0.15 and a polyethylene weight fraction in the feed of 0.11 [66]

proposed the use of a mixture of anthracite and high calorific waste plastics in an oxygen blown steam reforming process. Van Kasteren [66] carried out steam reforming of a mixture of biomass and PE for the production of synthesis gas (carbon monoxide and hydrogen). The aim was the direct fermentation of the product gas in order to obtain ethanol. The highest efficiency was $42 \%$ for carbon monoxide and hydrogen, and it was achieved at $900^{\circ} \mathrm{C}$ with a feed containing a low PE content of $11 \mathrm{wt} \%$ (Fig. 4). Mun et al. [67] gasified woody biomass with air in order to obtain a high calorific product gas. At $800^{\circ} \mathrm{C}$, the product gas reached a lower heating value of $10 \mathrm{MJ} \mathrm{Nm} \mathrm{[3]} \mathrm{because} \mathrm{of} \mathrm{its} \mathrm{high}$ hydrogen and methane content. The presence of activated carbon in the reactor reduced the tar content of the gas to one sixth.

Uemura et al. [68] proposed a process for the decomposition of waste plastics into hydrogen and carbon. In the first step, plastic waste materials are pyrolyzed, giving mainly hydrocarbons. In the second step, the pyrolysis gas is decomposed into hydrogen and carbon using a nickel catalyst. The second step was investigated by degrading propene using various alumina-supported nickel catalysts in a spouted bed reactor at $770^{\circ} \mathrm{C}$. Song et al. [69] obtained multiwalled carbon nanotubes from the reaction of $\mathrm{PP}$ over an organically modified montmorillonite and $\mathrm{Ni}_{2} \mathrm{O}_{3}$ at $700^{\circ} \mathrm{C}$. The carbonization of PP was supported by the formation of Brønsted acid sites in the montmorillonite layers during the decomposition of the organic modifiers. The formation of carbenium ions resulted in the reduction of the PP molecular weight, and $\mathrm{Ni}_{2} \mathrm{O}_{3}$ catalyzed the growth of the carbon nanotubes.

\section{Dehalogenation}

The dehalogenation of waste plastic materials is of special importance because of the damage halogenated compounds can cause to recycling facilities, petrochemical plants, and combustion engines because of the corrosive effect of $\mathrm{HCl}$. Moreover, the emission of halogenated compounds is a threat to the environment and human health. Polychlorinated dibenzodioxins (PCDDs), dibenzofurans (PCDFs), and biphenyls (PCBs) are listed as persistent organic pollutants (POPs). They are barely metabolized by organisms and remain in the environment for a long time, where they accumulate in fatty tissue and cause cancer if ingested. In order to prevent the release of these hazardous chlorinated compounds, a technique for the controlled degradation of halogen containing materials is essential.

The source of halogens in waste plastics can be divided into two main groups. Chlorinated polymers, such as PVC, polyvinylidene dichloride (PVDC), and polychloroprene, are the main sources of chlorine. Polybrominated compounds, such as tetrabromobisphenol-A (TBBPA), decabromo diphenylether (DPE), and decabromo diphenylethane (DDE), are still frequently used as flame retardants, even though halogen-free flame retardants are available. Since some electric appliances are used for a long time, the brominated flame retardants being processed now will still be present in the waste stream decades from now.

Over the years, three main strategies have been developed for the removal of halogens from waste plasticsthermal dehalogenation, the mechanochemical removal of halogens by a suitable absorbent, and wet dehalogenation in an appropriate basic solvent.

Fukushima et al. [70] carried out the dehydrochlorination of MSW using a single screw extruder. At a temperature of about $360^{\circ} \mathrm{C}$, the chlorine content was successfully reduced to less than $0.5 \mathrm{wt} \%$ in $2 \mathrm{~min}$. This was comparable to the results obtained from a twin screw extruder. Kakuta et al. [71] found that plasticizers and fillers reduce the dehydrochlorination yield and prolong the reaction time at 230 and $260^{\circ} \mathrm{C}$. Furthermore, they found that activated carbon with a surface area of about $1,700 \mathrm{~m}^{2} \mathrm{~g}^{-1}$ can be obtained from the carbonaceous residue after a preoxidation step at $300^{\circ} \mathrm{C}$ and subsequent activation with $\mathrm{KOH}$ at $800^{\circ} \mathrm{C}$. Uddin et al. [72] degraded mixed plastics at 360 and $380^{\circ} \mathrm{C}$ in the presence of an alumina-silica catalyst and iron oxides as a chlorine absorber. The catalyst reduced the reaction time, and the iron oxide reduced the chlorine content of the oil. As a result, it was assumed that iron chloride was formed. Masuda et al. [73] investigated the influence of various metal oxides on the dehydrochlorination behavior of $\mathrm{PVC}$ at 400 and $800^{\circ} \mathrm{C} . \mathrm{ZnO}, \mathrm{CaO}, \mathrm{PbO}$, and $\mathrm{La}_{2} \mathrm{O}_{3}$ reduced the formation of chlorobenzene, while $\mathrm{Fe}_{2} \mathrm{O}_{3}$ and $\mathrm{CeO}_{2}$ enhanced its formation. $\mathrm{ZnO}$ promoted the 
formation of carbonaceous residue, while the residue was reduced in the presence of $\mathrm{CaO}$. Bhaskar et al. [74, 75] developed a chlorine sorbent consisting of $90 \mathrm{wt} \% \mathrm{CaCO}_{3}$ and $10 \mathrm{wt} \%$ phenol resin. This sorbent was successfully used in the dehalogenation of mixed plastics consisting of polyolefins, high-impact PS (HIPS) containing a brominated flame retardant, and $\mathrm{PVC}$ at $430^{\circ} \mathrm{C}$. In the presence of the sorbent, halogen-free oil was obtained. However, the efficiency of the sorbent was reduced in the presence of PET, resulting in a halogen concentration of about $330 \mathrm{ppm}$ in the oil. While the sorbent reduced the oil yield from the polyolefin mixed plastics, the presence of PET increased the oil yield. By employing the sorbent in a pilot plant using a batch reactor, $50 \mathrm{~kg}$ of MSW was successfully dehydrochlorinated, and an oil with a chlorine content of $100 \mathrm{ppm}$ was obtained [76]. German et al. [77] investigated the interaction between PVC and polycarbonate and PET, respectively. It was found that various chlorinated compounds were formed. Small amounts of chlorobenzene and other chloroaryl and chloroalkylaryl compounds were obtained from polycarbonate. The degradation of PET resulted in the formation of significant amounts of chloroethylesters of benzoic and terephthalic acid (Fig. 5).

Park et al. [10] used the product gas from the dehydrochlorination of $\mathrm{PVC}$ at $250^{\circ} \mathrm{C}$ for the recovery of indium from liquid crystal display (LCD) powder containing $\mathrm{In}_{2} \mathrm{O}_{3}$. $\mathrm{In}_{2} \mathrm{O}_{3}$ formed in the presence of $\mathrm{HCl}$ volatile $\mathrm{InCl}_{3}$. In this way, $67 \%$ of the indium was recovered at a chlorination temperature of $350^{\circ} \mathrm{C}$.

Saeki et al. [78] ground PVC with a mixture of $\mathrm{CaO}$, $\mathrm{SiO}_{2}$, and $\mathrm{Al}_{2} \mathrm{O}_{3}$ to mechanochemically dehydrochlorinate it in a planetary mill. The composition was similar to that of slag and more efficient than $\mathrm{CaO}$ alone or $\mathrm{CaCO}_{3} \cdot \mathrm{CaO}$ acted as the dehydrochlorination agent, while $\mathrm{SiO}_{2}$ and $\mathrm{Al}_{2} \mathrm{O}_{3}$ were grinding aids. Complete dehydrochlorination was achieved after $4 \mathrm{~h}$ of mechanochemical treatment. Tongamp et al. [79] used calcium sulfate as a dehydrochlorination agent during the mechanochemical treatment of PVC with a planetary mill. The dehydrochlorination ratio was $95 \%$ after $4 \mathrm{~h}$ when $\mathrm{CaSO}_{4}$ was used, while only a dehydrochlorination ratio of $50 \%$ was observed in the presence of $\mathrm{CaSO}_{4} \cdot 2 \mathrm{H}_{2} \mathrm{O}$ after $8 \mathrm{~h}$ of milling. Hydrogen sulfide was released during the treatment. The mill power
Fig. 5 Formation of chloroderivatives from PET in the presence of $\mathrm{HCl}$ [77]
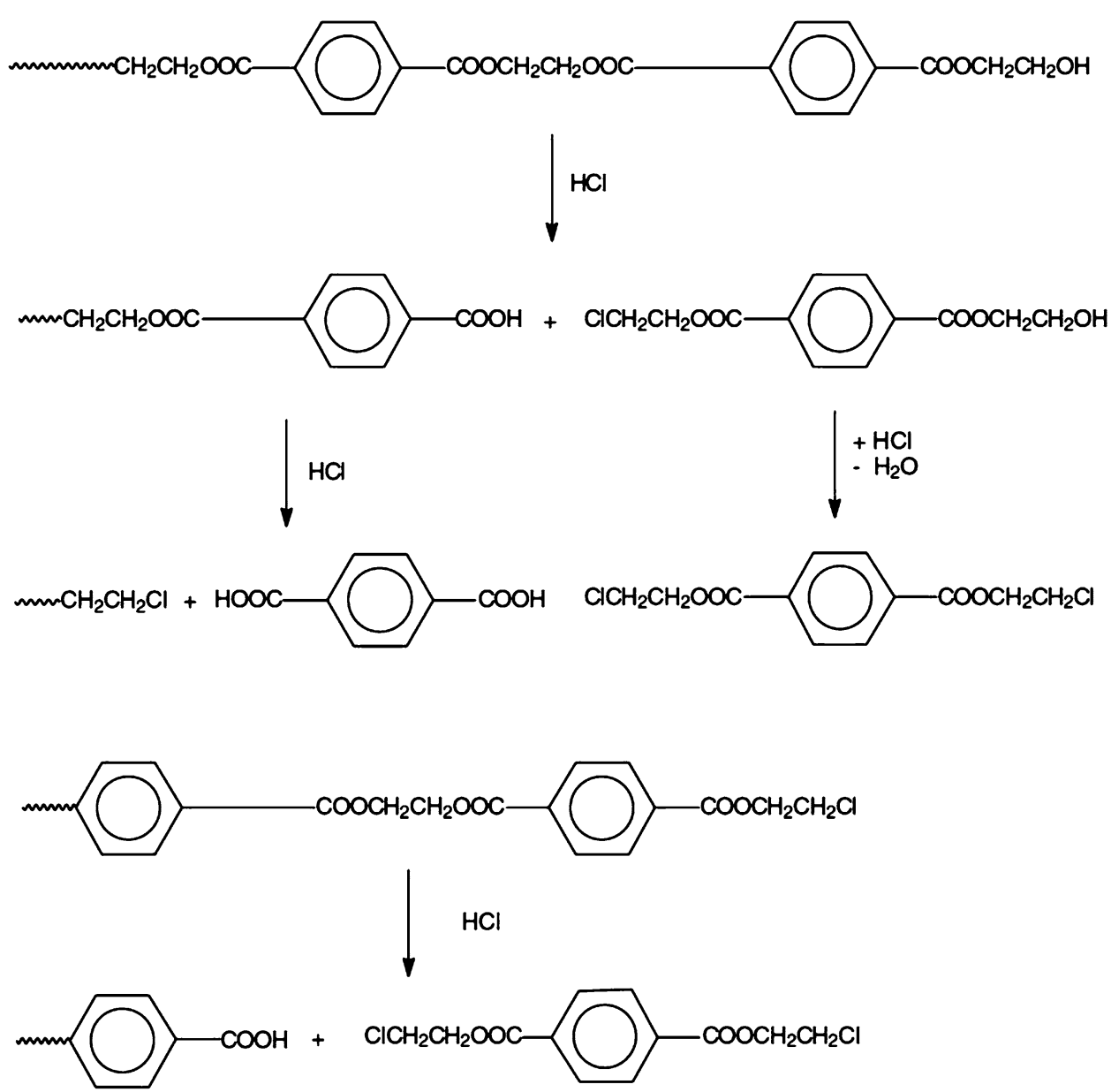
consumption was calculated by the discrete element method (DEM) $[9,80]$. It was found that the use of oyster shells $\left(\mathrm{CaCO}_{3}\right)$ was slightly more efficient than the use of $\mathrm{CaO}$. The complete dehydrochlorination of PVC was able to be achieved within 2 or $3 \mathrm{~h}$. After removing copper from automotive shredder residue (ASR), Endoh et al. [81] milled the PVC containing ASR in the presence of $\mathrm{CaO}$ and $\mathrm{CaCO}_{3}$. After $8 \mathrm{~h}$ milling, the chlorine content of the material was reduced to just one tenth of its original value.

Shin et al. [82, 83] dehydrochlorinated flexible and rigid PCV using aqueous $\mathrm{NaOH}$ solutions at temperatures between 150 and $250^{\circ} \mathrm{C}$. Complete dehydrochlorination was achieved at $250^{\circ} \mathrm{C}$ for flexible and rigid PVC after 3 and $5 \mathrm{~h}$, respectively. The highest dehydrochlorination rate was observed in 5 and $3 \mathrm{M} \mathrm{NaOH}$ for flexible and rigid PVC, respectively. The treatment of the rigid PVC left a residue with small pores of $2 \mu \mathrm{m}$ in size. After treatment, the flexible PVC pores were larger $(16 \mu \mathrm{m})$ because of the high content of plasticizer that was dissolved. In both cases, the reaction proceeded by a first order kinetics. Since the disadvantage of using aqueous solutions for the dehydrochlorination of PVC is that high pressure is required to reach the necessary reaction temperature, Yoshioka et al. [84] proposed ethylene glycol to be used instead of water. Its high boiling point of $196^{\circ} \mathrm{C}$ made it possible to carry out the reaction at atmospheric pressure. The reaction was faster than in aqueous solution and reached a dehydrochlorination yield of $98 \%$ at $190^{\circ} \mathrm{C}$. Elimination occurred during the reaction as well as the substitution of chlorine by hydroxy groups. Wu et al. [85] carried out the dehydrochlorination in polyethylene glycol (PEG) in the absence of a basic medium. From TG measurements, it was observed that the dehydrochlorination step of PVC occurred at lower temperatures in the presence of PEG. Dehydrochlorination in a batch reactor resulted in a dehydrochlorination yield of $74 \%$ after $1 \mathrm{~h}$ at a temperature of $210^{\circ} \mathrm{C}$. Osada and Yana [2] used an aqueous $\mathrm{NaOH}$ solution under microwave radiation for the dehydrochlorination of flexible PVC. Microwave heating has the advantage of a direct heat transfer into the reaction medium (Fig. 6). Molecular vibrations are directly activated, resulting in a reduced reaction time. Using microwave heating, the plasticizer was removed after $30 \mathrm{~min}$ at $150^{\circ} \mathrm{C}$, and complete dehydrochlorination was achieved at a temperature of $235^{\circ} \mathrm{C}$ for the same time using an $8 \mathrm{M} \mathrm{NaOH}$ solution. When ethylene glycol was used instead of water [3], the reaction temperature was reduced to $160^{\circ} \mathrm{C}$, and the reaction time was cut to $10 \mathrm{~min}$ at an $\mathrm{NaOH}$ concentration of $1 \mathrm{M}$. A method based on the dehydrochlorination of PVC in ethylene glycol was proposed by Kameda et al. [86] for the partial substitution of chlorine. The highest substitution yield was observed for the azido group at $66 \%$. Besides substitution, elimination was also observed. The substitution to elimination ratio followed the order hydroxy $>$ azido $=$ thiocyanato $>$ phthalimido $>$ iodo group. Yoshihara et al. [87] found that the reaction of PVC with $\mathrm{Na}_{2} \mathrm{~S}$ resulted in the elimination of $32 \%$ of the chloride and the substitution of $26 \%$ of it. The bivalent $\mathrm{S}^{2-}$ formed exclusively cross-linked sulfur bridges, which were mainly located close to the surface of the PVC particles, preventing the further penetration of the particles by the solvent.

Peng et al. [88] investigated the pyrolysis of TV housing plastics containing brominated flame retardants. It was found that the flame retardant decomposed between 280 and $350^{\circ} \mathrm{C}$, while the degradation of HIPS took place between 350 and $450^{\circ} \mathrm{C}$. The removal of $90 \%$ of flame retardant-related products was possible at temperatures just above $280^{\circ} \mathrm{C}$ using a vacuum below $5 \mathrm{kPa}$. At temperatures higher than $300^{\circ} \mathrm{C}$, the degradation of the HIPS matrix has to be expected. The thermal degradation of flame-retarded HIPS was investigated by Jakab et al. [89]. The flame retardants DPE and DDE did not change the thermal stability of the polymer, while the synergist $\mathrm{Sb}_{2} \mathrm{O}_{3}$ reduced thermal stability by about $50 \mathrm{~K}$. Various brominated diphenylethers and dibenzofurans were observed as degradation products. Bhaskar et al. [90] investigated the effect of the pyrolysis of HIPS containing DDE as a brominated flame retardant on the degradation of a plastic mixture consisting of PP, PE, and PS. The reaction was carried out with two heating steps at 330 and $430^{\circ} \mathrm{C}$. Brominated compounds were mainly observed at $330^{\circ} \mathrm{C}$. The presence of the synergist $\mathrm{Sb}_{2} \mathrm{O}_{3}$ led to a significant alteration of the product distribution. The copyrolysis of PET and flame-retarded HIPS resulted in a rise in
Fig. 6 The difference in the mechanism of conventional heating and microwave heating [2]

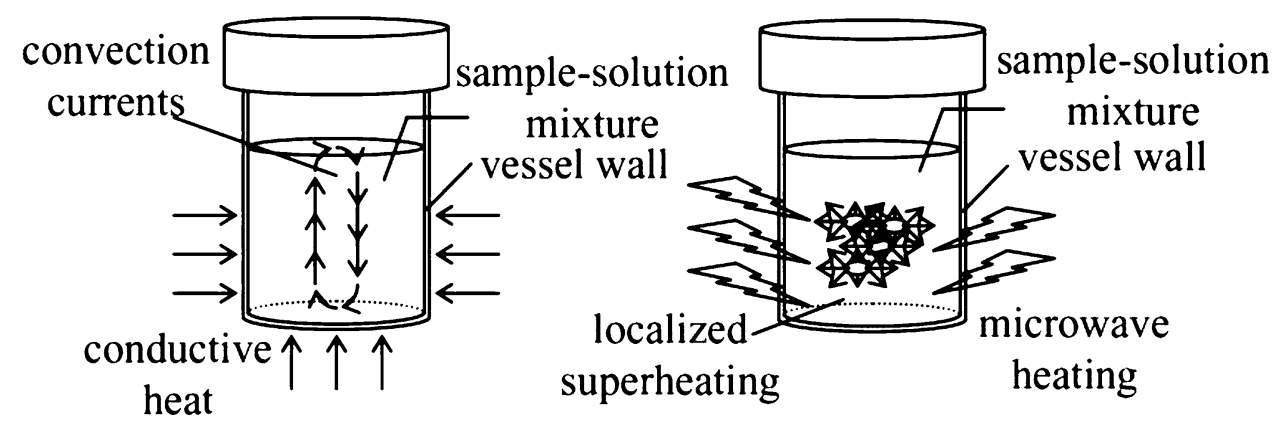


brominated organic products. Even a small amount of PET increased the release of brominated compounds by several times. Mitan et al. [91] debrominated sole flame-retarded HIPS and acrylonitrile-butadiene-styrene copolymer and a blend of both polymers using various catalytic systems at $430^{\circ} \mathrm{C}$. Considering the high oil and gas yield as well as low bromine content of the oil, the best results were obtained when mesoporous silica (FSM) was in contact with the liquid phase and a $\mathrm{CaOH}-$ composite $(\mathrm{CaHC})$ was in contact with the gas phase. Brebu and Sakata [92] used ammonia for the debromination of flame-retarded HIPS at $450^{\circ} \mathrm{C}$. Inorganic bromide was fixed as $\mathrm{NH}_{4} \mathrm{Br}$ and recovered as a solid from the oil. Ammonia was not able to improve the removal of the organic bromine left in the oil. Luda et al. [93] found that the thermal degradation of TBBPA mainly took place in a temperature range between 270 and $340^{\circ} \mathrm{C}$. $\mathrm{HBr}$ and brominated phenols and bisphenols were observed as the products, while large amounts of carbonaceous residue remained due to condensation reactions. Dibenzodioxin structures were found in the residue. However, they were not released. Futamura and Zhang [94] decomposed flameretarded computer casings in tetralin between 380 and $400^{\circ} \mathrm{C}$. Activated carbon acted as a catalyst, transferring hydrogen from tetralin to the plastic. No brominated organic compounds, such as polybrominated dibenzodioxins, were observed. The product oil mainly consisted of aromatic compounds.

\section{Chemolysis and solvent processes}

Many polymeric materials can be treated with solvent systems, which fulfill several tasks. The solvent provides better heat and mass transport properties compared with thermal degradation by itself. Solvents might also function as reactants during hydrolysis, methanolysis, and glycolysis. Moreover, at higher temperatures water exhibits excellent solvation properties, making it possible to dissolve materials that have low solubility at lower temperatures.

The general term for processes in which the solvent also acts as a reactant is solvolysis. Notably, plastics containing reactive groups can be depolymerized by solvolytic processes. Polycarbonate and PET possess ester bonds that undergo hydrolysis and transesterification in the presence of water and alcohols, respectively. Other polymers decompose in inert solvents at high temperatures by thermal degradation without the fission of reactive groups.

The advantage of solvolysis is the possibility to recover monomers at a relatively low temperature, thus allowing them to be chemically modified in some cases, depending on the solvent used. However, fillers and additives might have a negative impact on the process, making it difficult to use the solvent for a long time without regeneration.
The classical field for solvolysis is the depolymerization of PET. Methanolysis was carried out by Goto et al. [95]. The reaction was carried out in a batch reactor with supercritical methanol at a temperature of $300^{\circ} \mathrm{C}$ and a pressure of $20 \mathrm{MPa}$. The molecular weight of the PET decreased with time and reached 1,000 Da after $10 \mathrm{~min}$. The highest yield of dimethylterephthalate (DMT) $(80 \%)$ was obtained after $2 \mathrm{~h}$. Genta et al. [96] proposed a kinetic model in which PET undergoes at first a random scission in the heterogeneous phase, which results in the formation of oligomers. After that, the oligomers react in the homogeneous phase with methanol from the chain ends, forming DMT. Lopez-Fonseca et al. [97] carried out the glycolysis of PET with an excess of ethylene glycol at $196^{\circ} \mathrm{C}$ using various catalysts. After $8 \mathrm{~h}$, bis(2-hydroxyethyl) terephthalate with a yield of about $70 \%$ was obtained in the presence of zinc acetate and sodium carbonate. The use of sodium carbonate was suggested as an eco-friendly catalyst for the glycolysis of PET. Oku et al. [98] used ethylene glycol as a solvent for the alkaline hydrolysis with $\mathrm{NaOH}$ at temperatures between 150 and $180^{\circ} \mathrm{C}$. PET was quantitatively converted into disodium terephthalate after 80 and $15 \mathrm{~min}$ at 150 and $180^{\circ} \mathrm{C}$, respectively. The reaction was significantly enhanced by the addition of ethers, such as dioxan, tetrahydrofuran, and dimethoxyethan. Spychaj et al. [99] depolymerized PET in the presence of various polyamins between 200 and $210^{\circ} \mathrm{C}$. The resulting polyamine can be used as a component in the production of reactive resins, i.e., epoxy resins. The use of triethanolamine for the depolymerization of PET resulted in a polyol that can be used for the production of polyurethanes (Fig. 7). Mohd-Adnan et al. [100] investigated the hydrolysis of poly(L-lactic acid) in pressurized steam between 100 and $130^{\circ} \mathrm{C}$ in an autoclave. It was found that the initial homogeneous random degradation process changed at $130{ }^{\circ} \mathrm{C}$ after about $45 \mathrm{~min}$ and molecular weight average of about $5,000 \mathrm{~g} \mathrm{~mol}^{-1}$ to a heterogeneous degradation process. The activation energy increased with the weight loss.

Fiber-reinforced plastics (FRPs) consist mainly of glass or carbon fibers embedded in a matrix of unsaturated polyesters cross-linked by styrene. Iwaya et al. [101] depolymerized FRP in subcritical benzyl alcohol and diethyleneglycol monomethylether between 190 and $350^{\circ} \mathrm{C}$ in the presence of $\mathrm{K}_{3} \mathrm{PO}_{4}$ as a catalyst. Benzaldehyde and benzoic acid were identified as polyester-related products, styrene derivatives as products from PS. The fibers were successfully recovered for reuse. Kamimura et al. [102105] used supercritical methanol for the degradation of FRP between between 250 and $275^{\circ} \mathrm{C}$. $N, N$-dimethylaminopyridine was found to be an efficient catalyst. The main products of the methanolysis were dimethylterephthalate and propylene glycol. The products obtained from the 

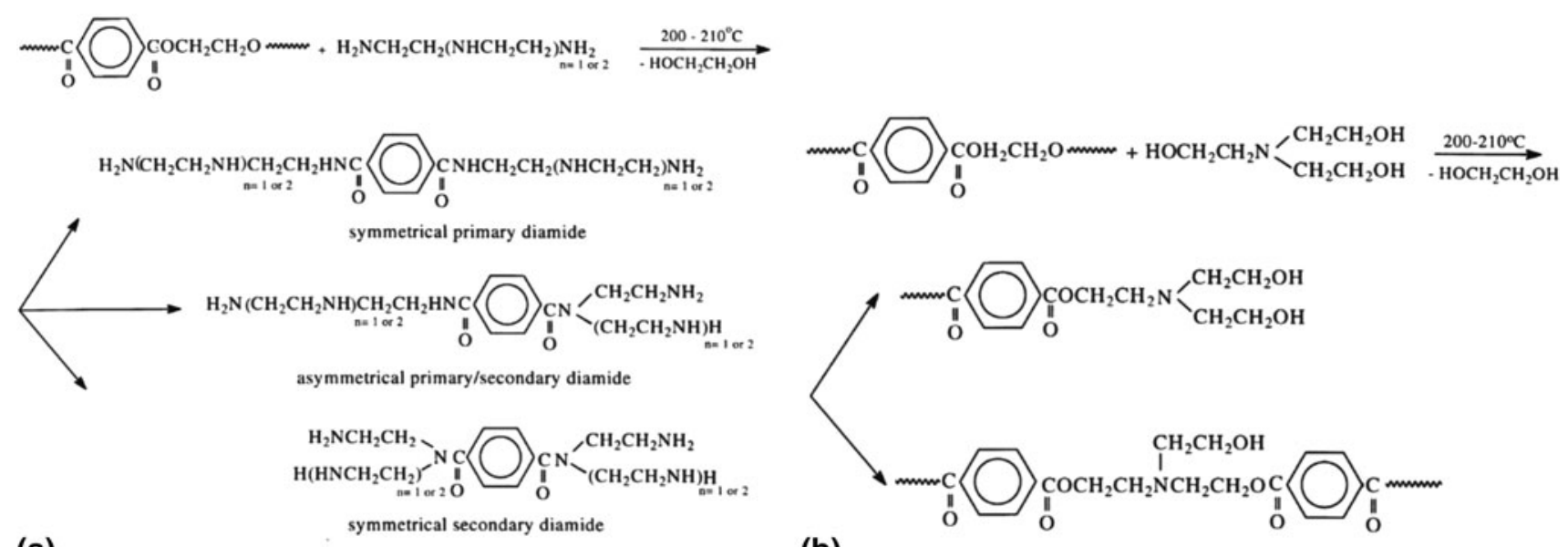

(a)

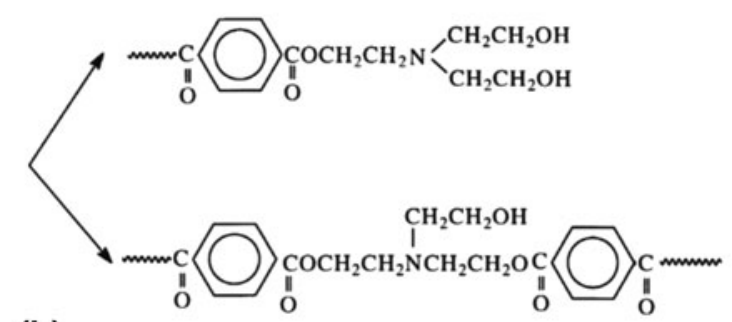

(b)

Fig. 7 Degradative reaction of PET with a polyamines and b triethanolamine [99]

depolymerization were used for the synthesis of new FRP, which exhibited similar properties to commercial FRP. The product quality was improved by the reduction of the amount of catalyst and the purification of the methanolysis products by activated carbon. The preparation of FRP from the recovered monomers using calcium acetate and titanium tetrabutyrate as catalysts provided a product with mechanical properties comparable to FRP obtained from new monomers.

Hu et al. [106] used various unpolar solvents as additives for the methanolysis of polycarbonate. While the reaction of polycarbonate in methanol and in the presence of a catalytic amount of $\mathrm{NaOH}$ yielded only $7 \% \mathrm{BPA}$ at $60^{\circ} \mathrm{C}$ after $330 \mathrm{~min}$, the same reaction was completed after $70 \mathrm{~min}$ with the addition of toluene. The reaction also yielded $100 \%$ of the dimethylcarbonate. A similar reaction with glycerol and $\mathrm{KOH}$ as a catalyst in dry dioxane at $100^{\circ} \mathrm{C}$ resulted in high yields of 4-(hydroxymethyl)-1,3-dioxolan-2-one and BPA after 25 min [107]. The reaction of glucose with polycarbonate in pyridine resulted in glucose dicarbonate with a yield of $46 \%$. Kim et al. [108] carried out the depolymerization of polycarbonate in ethylene glycol at $220^{\circ} \mathrm{C}$ for $85 \mathrm{~min}$. High yields of BPA and ethylene glycol carbonate were obtained with an ethylene glycol/polycarbonate ration of 4. It was found that the glycolysis of polycarbonate proceeded much in the same way as the methanolysis of PET [96]. Margon et al. [109, 110] investigated the equilibrium conditions of the polycarbonate decomposition products diphenylcarbonate (DPC) and BPA after the degradation of polycarbonate in phenol, as well as the extraction of these products in supercritical carbon dioxide. The Peng-Robinson equation of state (PR EOS) binary interaction parameters of the systems DPC-carbon dioxide, BPA-carbon dioxide, phenol-DPC, phenol-PBA, and DPC-BPA were used to develop a model of the tertiary system phenol-DPC-BPAcarbon dioxide. This model allowed the extraction behavior of the different compounds in this system to be predicted. Sato et al. [111] carried out the thermal degradation of polycarbonate in tetralin, decalin, and cyclohexanone under pressure. The thermal degradation resulted at $440^{\circ} \mathrm{C}$ in high yields of phenol and isopropenylphenol. Between 300 and $350^{\circ} \mathrm{C}$, high yields of BPA were recovered. The addition of $\mathrm{CaCO}_{3}$ was necessary in order to maintain the reaction.

Molero et al. [112, 113] obtained mainly oligomeric polyols from the glycolysis of polyurethane at $189^{\circ} \mathrm{C}$. The reaction was carried out in "split phase," involving two phases that are formed during the reaction. The produced polyols remain separated in the upper layer of the reaction mixture. Potassium octoate was found to behave as a catalyst with high activity, leading to the complete dopolymerization of polyurethane within $2 \mathrm{~h}$. This process also showed a high selectivity for glycolysis and resulted in little hydrolysis. Troev et al. [114] used triethyl phosphate for the depolymerization of polyurethane at $190^{\circ} \mathrm{C}$. The resulting oligomers contained about 8 wt $\%$ phosphor.

Tagaya et al. [115] used several model compounds in order to investigate the mechanism of the degradation of phenol resins in sub- and supercritical water. The addition of tetralin had a positive effect on the degradation of bis(o-hydroxyphenyl)-methane. Alkali salts acted as catalysts. Water acted not only as the reaction medium, but also as a reactant, causing the oxidation of methylene groups. Shibasaki et al. [116] degraded aromatic ethers in sub- and supercritical water between 250 and $430^{\circ} \mathrm{C}$. $\mathrm{Na}_{2} \mathrm{CO}_{3}$ was present as a catalyst. The main products obtained were phenolic compounds from aromatic ethers and benzyl aldehyde and benzyl alcohol from dibenzylether. The water content and temperature had a significant influence on the reaction.

Moriya and Enomoto [117] investigated the degradation of PE in supercritical water. The reaction proceeded more slowly in the initial stage than during thermal degradation. However, less char was produced during the hydrothermal 
treatment. The products obtained were mainly alcohols and ketones. Aguado et al. [118] degraded HDPE in decalin at $400^{\circ} \mathrm{C}$ and $2 \mathrm{MPa}$ in nitrogen atmosphere. Due to an improved heat and mass transfer, more gas and oil and less solid were obtained compared with the reaction without decalin. Decalin enhanced the production of $\alpha$-olefins and $n$-parafins.

Chen et al. [119] conducted the depolymerization of nylon- 6 in subcritical water between 280 and $330^{\circ} \mathrm{C}$. The use of phosphotungsten heteropoly acid as a catalyst resulted in high yields of $\varepsilon$-caprolactam with 6-aminocaproic acid and oligomers as minor products. The highest yield of $78 \%$ of $\varepsilon$-caprolactam was achieved at $300^{\circ} \mathrm{C}$ after a reaction time of $85 \mathrm{~min}$.

Du et al. [120] used a system of PEG and $\mathrm{NaOH}$ for the denitrogenation of acrylonitrile-butadiene-styrene (ABS), dissolved in tetrahydrofurane, dioxane, or toluene. After $2 \mathrm{~h}$ of reaction time at $160^{\circ} \mathrm{C}, 93 \%$ of the initial nitrogen was removed from the ABS material when tetrahydrofuran was used as a solvent.

Wahyudiono et al. [121] decomposed lignin in supercritical water between 380 and $400^{\circ} \mathrm{C}$. Catechol, phenol, and $o$-cresol were the main products of the guaiacol degradation with catechol reaching more than $40 \mathrm{wt} \%$. Long reaction times caused the production of char. Increasing water density accelerated the product formation. Kamo et al. [122] obtained tar from the reaction of wood from Japanese cedar with benzyl alcohol and $\mathrm{NaOH}$ or cresol and sulfuric acid at temperatures between 250 and $350^{\circ} \mathrm{C}$. Various plastic materials were solubilized in the resulting tar. Epoxy resin from printed circuit boards was almost completely solubilized at temperatures between 250 and $300^{\circ} \mathrm{C}$. Tanaka et al. [123] extracted dietary fibers from the juice processing residue of Citrus junos. This material, high in pectin, hemicelluloses, and cellulose, was treated with subcritical water between 160 and $320^{\circ} \mathrm{C}$. About $78 \%$ of the pectin and $80 \%$ of the cellulose were extracted at 160 and $200^{\circ} \mathrm{C}$, respectively.

\section{Other recycling technologies}

The majority of contributions for the ISFR were dedicated to the chemical recycling of plastics. Over the course of time, the ISFR gradually widened its field of interest to areas not directly connected with the classical process of feedstock recycling resulting in petrochemical oils and monomers for the chemical industry. Mechanical recycling, including material separation, blending, etc., was given more space.

The most obvious difference from chemical recycling is that mechanical recycling attempts to conserve the chemical structure of the polymer. The aim is to remove the additives and fillers without destroying the polymer backbone. In order to obtain a useful recyclate, it is necessary to provide a sorted polymer fraction. For this reason, various separation techniques are applied. Since the properties of recyclates differ in general from those of the initial polymer, they are often blended with virgin materials in order to meet certain specifications.

Various separation techniques were introduced during ISFR symposia. Gondal and Siddiqui [124] applied laserinduced breakdown spectroscopy (LIBS) for the identification of various polymers. Laser-produced plasma emissions allowed the identification of the major plastics HDPE, LDPE, PP, PS, PET, and PVC by their carbon/hydrogen ratio. LIBS allows these plastic to be identified in real time. Reddy et al. [8] used froth flotation for the separation of PVC and PET from other plastics. After employing surface ozonation, $90 \%$ of $\mathrm{PVC}$ and PET were floating at $40^{\circ} \mathrm{C}$. At a mixing velocity of $180-200 \mathrm{rpm}$, the PVC settled, while PET floated at the surface. Weiß et al. [125] used highpressure water jets for the removal of latex binders and other materials from textiles. This method was specifically designed with the treatment of waste carpets and automotive interior materials in mind. It is applicable to materials consisting of fibers embedded in a matrix with a lower critical threshold pressure than the fibers themselves.

Garcia et al. [126] used various solvents for the dissolution of extruded PS in order to reduce the volume of the material. It was found that the similar polarity of structurally similar terpenoids provided them with the best dissolution properties. Their solubility increased with the rise in temperature. However, at $60^{\circ} \mathrm{C}$, a slight degradation of the PS was observed. Furgiuele et al. [127] reduced the volume of PP/PS blends by solid state shear pulverization. Below melt and glass transition temperature, a fine powder was obtained. The high shear rates were suspected of resulting in the fission of the polymer backbone, resulting in block copolymers. The successful blending of both polymers was confirmed by the reduction of the glass transition temperature of the PS-rich phase. Inagaki et al. [128] sulfonated PS from PS foam and TV cabinets in order to obtain a water-soluble polymer that could be used as a flocculant in waste water treatment. It was found that sulfonated PS (PSS) with a medium viscosity was efficient in the treatment of industrial inorganic waste waster, while highly viscous PSS was suitable for use in the dewatering of domestic waste water (Fig. 8). Garcia et al. [129] investigated the properties of blends between PVC recyclate and virgin and recycled styrenic polymers, styrene acrylonitrile (SAN) and acrylonitrile-butadiene-styrene (ABS). PVC-SAN blends showed improved resistant mechanical properties and reduced ductile properties, while PVC-ABS blends had improved ductility.

Zhang et al. [130, 131] devulcanized ground tire rubber mechanochemically by grinding with a self-designed pan- 
Fig. 8 Flow sheet for waste PS as a flocculant for waste water treatment [128]

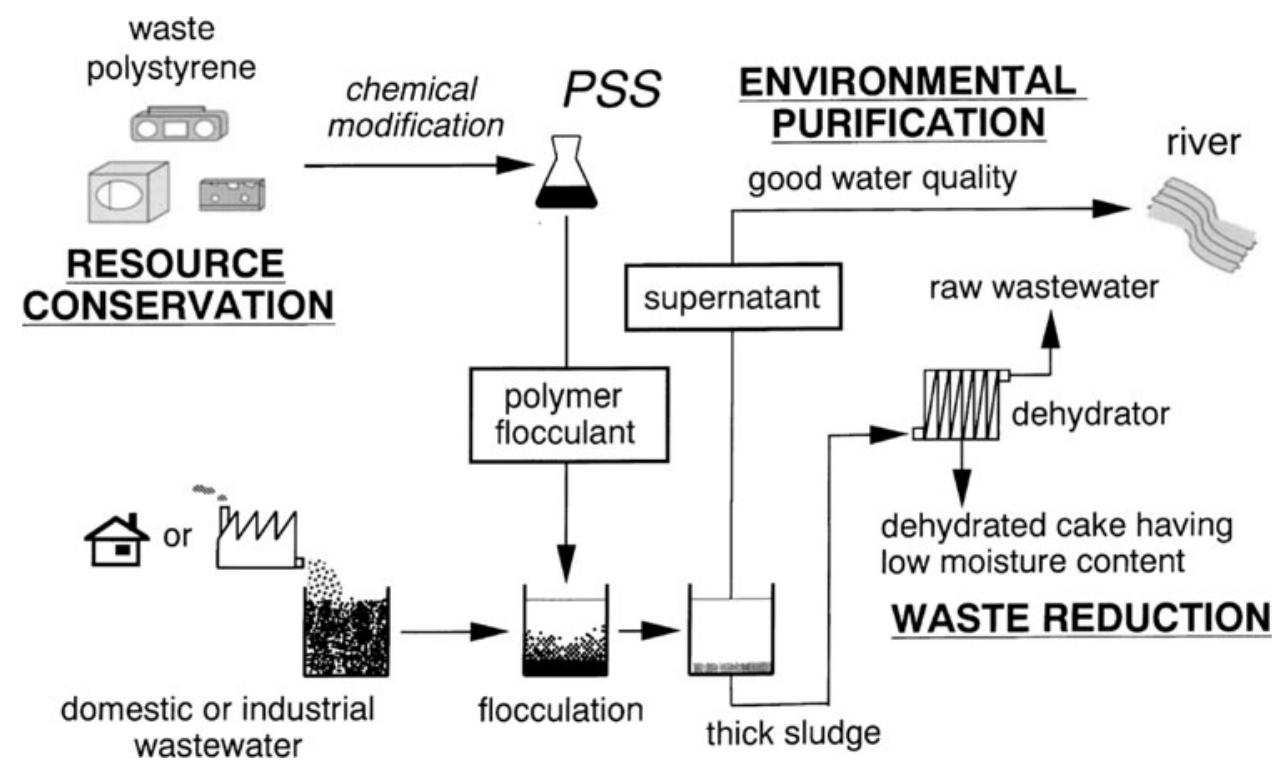

mill. The partly devulcanized rubber was blended with natural rubber in various ratios. The blends showed excellent tensile properties. Ground tire rubber was blended with LDPE using solid-state shear milling and azodicarbonamide as a chemical blowing agent. The differences in the glass transition temperature of the soft elastomer segment and the hard thermoplast segment became smaller, indicating that rubber and LDPE were more compatible after milling.

Silva Spinacé and de Paoli [132] investigated the impact of repeated processing with a single screw extruder. The mechanical properties and the crystallinity degree changed drastically during the first three cycles. The melt flow index and the number of carboxylic end groups increased, indicating mechanochemical degradation. However, no changes in the thermal stability were observed after five cycles.

Chong et al. [133] used oyster shells coated with cetyltriammonium bromide as a flame retardant for recycled PE. The flame retardancy was attributed to the decomposition of $\mathrm{CaCO}_{3}$ at temperatures of more than $800^{\circ} \mathrm{C}$. The mechanical properties of the composite material improved with the addition of the oyster shells. Recycled PE with an oyster shell content of more than $30 \mathrm{wt} \%$ fulfilled the classification of V-0, according to the UL 94 specification. Sridhar et al. [134] synthesized fly ash reinforced thermoplastic vulcanizates from waste tire powder. The thermal stability increased with the fly ash content. The mechanical properties were investigated as well.

\section{Outlook}

Over the last decade, progress has been made in many fields of plastic recycling. The aim has always been to improve the quality of the products obtained from waste materials. The larger the effort for the treatment of waste, the higher the recovered product has to be in price in order for the effort to be considered economically feasible. The lowest effort possible is that required for improving mechanical recycling techniques. However, mechanical recycling sets high standards for the material to be recycled, making it viable only for a few applications. Downcycling is an effect often observed during the mechanical recycling of plastics. The newly gained possibility of producing food grade recycled PET is promising, however, as is the Vinyloop process for the recycling of PVC [135].

More effort is necessary for the chemical recycling of polymers. The recovery of monomers is only feasible for pure polymers, which must be gathered in large quantities or are otherwise expensive. The combination of the separated collection of PET with the bottle-to-bottle glycolysis AIES process as it is realized in Japan is a good example for future recycling systems. The liquefaction of MSW is still struggling because of the effort required to provide acceptable oil qualities. The removal of heteroatoms such as halogens, sulfur, and nitrogen makes it expensive to produce oil from waste plastics. The competitive production of synthetic crude oil is hindered by the limitation posed by the size of the processing facilities, at just one tenth the size of a typical petrochemical plant. This can be attributed to the lack of availability of waste plastics-only $6 \%$ of the crude oil production goes into the chemical sector. Therefore, research on the possibilities of processing mixtures of plastics with high boiling fractions from the crude oil rectification [24] is an important way of finding new processing strategies. It must be remembered, however, that the emission of hazardous substances from plastic waste treatment is an environmental concern that 
can threaten the acceptance of such processes among the population [136, 137].

For all these reasons, regulative measures have been taken in order to come to a sustainable use of resources [138]. Sustainability means that resources are used in a way that the environmental system is able to recover from our interference. Our world is ruled by the economic interests of the individual, which do not include the quality of life and other intangible values. Sustainability, however, requires financial support without the opportunity of directly profiting from this investment, and therefore, it is uneconomical. On the other hand, sustainability has an impact on the quality of life of whole populations, since it reduces the environmental burden derived from products consumed and put to use in our daily lives, and therefore, sustainability is highly desirable. This can only be reached with the implementation of regulations and provision of financial incentives. Limitations for land filling, the dismantling of end-of-life-vehicles [139], and extended producer responsibility [138] are important steps for a recycling-oriented society. A new approach was seen recently by the EU Commissioner for Fisheries, Maria Damanaki, when she suggested paying the fishing industry for fishing the debris that pollutes the world's oceans. This does not result in financial gain for those who pay these actions, but it makes life better.

The bottom line is that waste material contains many valuable materials: gold, silver, platinum, copper, and other rare metals are present in WEEE; and PMMA is a monomer, which has been recovered for decades by depolymerization [31]. The task in the coming decade is to add to the list of materials and substances considered worthy of being recovered.

Open Access This article is distributed under the terms of the Creative Commons Attribution Noncommercial License which permits any noncommercial use, distribution, and reproduction in any medium, provided the original author(s) and source are credited.

\section{References}

1. Okuwaki A (2001) Overview. J Mater Cycles Waste Manage 3:1

2. Osada F, Yana J (2010) Deplasticization and dechlorination of flexible polyvinyl chloride in $\mathrm{NaOH}$ solution by microwave heating. J Mater Cycles Waste Manage 12:245-253

3. Osada F, Yoshioka T (2009) Dechlorination of polyvinyl chloride in $\mathrm{NaOH} /$ ethylene glycol solution by microwave heating. J Mater Cycles Waste Manage 11:19-22

4. Liu F, Li L, Yu S, Lv Z, Ge X (2011) Methanolysis of polycarbonate catalysed by ionic liquid [Bmim][Ac]. J Hazard Mater 189:249-254

5. Liu F, Cui X, Yu S, Li Z, Ge X (2009) Hydrolysis reaction of poly(ethylene terephthalate) using ionic liquids as solvent and catalyst. J Appl Polym Sci 114:3561-3565

6. Yamamoto S, Kamimura A (2009) Preparation of novel functionalized ammonium salts that effectively catalyze depolymerization of nylon-6 in ionic liquids. Chem Lett 38:1016-1017
7. Zhao T, Zhou Q, He X-L, Wei S-D, Wang L, van Kasteren JMN, Wang Y-Z (2010) A highly efficient approach for dehydrochlorinating polyvinyl chloride: catalysis by 1-butyl-3-methylimidazolium chloride. Green Chem 12:1062-1065

8. Reddy M, Okuda T, Kurose K, Tsai T-Y, Nakai S, Nishijima W, Okada M (2010) Surface ozonation of polyvinyl chloride for its separation from waste plastic mixture by froth floatation. J Mater Cycles Waste Manage 12:326-331

9. Tongamp W, Kano J, Suzuta Y, Saito F, Themelis N (2009) Relation between mechanochemical dechlorination rate of polyvinyl chloride and mill power consumption. J Mater Cycles Waste Manage 11:32-37

10. Park K-S, Sato W, Grause G, Kameda T, Yoshioka T (2009) Recovery of indium from $\operatorname{In}_{2} \mathrm{O}_{3}$ and liquid crystal display powder via a chloride volatilization process using polyvinyl chloride. Thermochim Acta 493:105-108

11. Buekens AG, Schoeters JG (1998) Technical methods in plastics pyrolysis. Macromol Symp 135:63-81

12. Kaminsky W, Predel M, Sadiki A (2004) Feedstock recycling of polymers by pyrolysis in a fluidised bed. Polym Degrad Stab 85:1045-1050

13. Jung S-H, Cho M-H, Kang B-S, Kim J-S (2010) Pyrolysis of a fraction of waste polypropylene and polyethylene for the recovery of BTX aromatics using a fluidized bed reactor. Fuel Process Technol 91:277-284

14. Kodera Y, Ishihara Y, Kuroki T (2005) Novel process for recycling waste plastics to fuel gas using a moving-bed reactor. Energy Fuels 20:155-158

15. Vasile C, Brebu MA, Karayildirim T, Yanik J, Darie H (2006) Feedstock recycling from plastic and thermoset fractions of used computers (I): pyrolysis. J Mater Cycles Waste Manage 8:99-108

16. Sugano M, Komatsu A, Yamamoto M, Kumagai M, Shimizu T, Hirano K, Mashimo K (2009) Liquefaction process for a hydrothermally treated waste mixture containing plastics. J Mater Cycles Waste Manage 11:27-31

17. Vasile C, Brebu M, Darie H, Cazacu G (2010) Effect of some environmentally degradable materials on the pyrolysis of plastics II: influence of cellulose and lignin on the pyrolysis of complex mixtures. J Mater Cycles Waste Manage 12:147-153

18. Tsuji T, Hasegawa K, Masuda T (2003) Thermal cracking of oils from waste plastics. J Mater Cycles Waste Manage 5:102-106

19. Mitan NMM, Brebu M, Bhaskar T, Muto A, Sakata Y, Kaji M (2007) Co-processing of DVDs and CDs with vegetable cooking oil by thermal degradation. J Mater Cycles Waste Manage 9:62-68

20. Bhaskar T, Mitan N, Onwudili J, Muto A, Williams P, Sakata Y (2010) Effect of polyethylene terephthalate (PET) on the pyrolysis of brominated flame retardant-containing high-impact polystyrene (HIPS-Br). J Mater Cycles Waste Manage 12:332-340

21. Yasuda H, Kamo T, Adachi M, Sajima S, Nakagome H (2010) Rapid hydropyrolysis of model compounds for epoxy resin oligomers and biomass tar. J Mater Cycles Waste Manage $12: 123-127$

22. Murata K, Sato K, Sakata Y (2004) Effect of pressure on thermal degradation of polyethylene. J Anal Appl Pyrolysis 71:569-589

23. Williams PT, Williams EA (1998) Interaction of plastics in mixed-plastics pyrolysis. Energy Fuels 13:188-196

24. Karayildirim T, Yanik J, Uçar S, Saglam M, Yüksel M (2001) Conversion of plastics/HVGO mixtures to fuels by two-step processing. Fuel Process Technol 73:23-35

25. Hájeková E, Bajus M (2005) Recycling of low-density polyethylene and polypropylene via copyrolysis of polyalkene oil/ waxes with naphtha: product distribution and coke formation. J Anal Appl Pyrolysis 74:270-281 
26. Shioya M, Kawanishi T, Shiratori N, Wakao H, Sugiyama E, Ibe $\mathrm{H}$, Abe $\mathrm{T}$ (2005) Development of waste plastics liquefaction technology feedstock recycling in Japan. In: Müller-Hagedorn M, Bockhorn H (eds) Feedstock recycling of plastics. Universitätsverlag Karlsruhe, Karlsruhe, pp 19-26

27. Fukushima M, Shioya M, Wakai K, Ibe H (2009) Toward maximizing the recycling rate in a Sapporo waste plastics liquefaction plant. J Mater Cycles Waste Manage 11:11-18

28. Kawanishi T, Shiratori N, Wakao H, Sugiyama E, Ibe H, Shioya M, Abe T (2005) Upgrading of Light Thermal Cracking Oil Derived from Waste Plastics in Oil Refinery. In: MüllerHagedorn M, Bockhorn H (eds) Feedstock recycling of plastics. Universitätsverlag Karlsruhe, Karlsruhe, pp 43-50

29. Wu B, Fukushima M, Wakai K, Ibe H, Ito S (2009) Current issues of oil reclamation system for recycling municipal waste plastic containing PVC and PET in Japan. In: The 5th symposium on feedstock and mechanical recycling of polymeric materials (ISFR2009). Chengdu (China), pp 89-95

30. Kato K, Nomura S, Uematsu H (2003) Waste plastics recycling process using coke ovens. J Mater Cycles Waste Manage 5:98-101

31. Smolders K, Baeyens J (2004) Thermal degradation of PMMA in fluidised beds. Waste Manage (Oxford) 24:849-857

32. Kang B-S, Kim SG, Kim J-S (2008) Thermal degradation of poly(methyl methacrylate) polymers: Kinetics and recovery of monomers using a fluidized bed reactor. J Anal Appl Pyrolysis $81: 7-13$

33. Sasaki A, Tsuji T (2009) Poly(methyl methacrylate) pyrolysis by two fluidized bed process. In: The 5th symposium on feedstock and mechanical recycling of polymeric materials (ISFR2009). Chengdu (China), pp 79-83

34. Kim S, Lee SW, Yu TU (2007) Identification of Pyrolysis Reaction Model of Poly(methyl methacrylate) (PMMA). In: 4th international symposium on feedstock recycling of plastics and other polymeric materials. Jeju Island (South Korea), pp 359-364

35. Lee K-H, Shin D-H, Seo Y-H (2004) Liquid-phase catalytic degradation of mixtures of waste high-density polyethylene and polystyrene over spent FCC catalyst. Effect of mixing proportions of reactants. Polym Degrad Stab 84:123-127

36. Vasile C, Pakdel H, Mihai B, Onu P, Darie H, Ciocâlteu S (2001) Thermal and catalytic decomposition of mixed plastics. J Anal Appl Pyrolysis 57:287-303

37. Nishino J, Itoh M, Ishinomori T, Kubota N, Uemichi Y (2003) Development of a catalytic cracking process for converting waste plastics to petrochemicals. J Mater Cycles Waste Manage 5:89-93

38. Ino H, Matsumoto Y, Takahashi R, Takami K, Nishino J, Itoh M (2008) Aromatization of waste polyolefin pyrolysate over H-ZSM-5 zeolite-supported gallium oxide catalysts. J Mater Cycles Waste Manage 10:129-133

39. Serrano DP, Aguado J, Escola JM, Rodriguez JM, Morselli L, Orsi R (2003) Thermal and catalytic cracking of a LDPE-EVA copolymer mixture. J Anal Appl Pyrolysis 68-69:481-494

40. Serrano DP, Aguado J, Escola JM, Rodríguez JM, San Miguel G (2005) An investigation into the catalytic cracking of LDPE using Py-GC/MS. J Anal Appl Pyrolysis 74:370-378

41. Karagöz S, Karayildirim T, Uçar S, Yuksel M, Yanik J (2003) Liquefaction of municipal waste plastics in VGO over acidic and non-acidic catalysts. Fuel 82:415-423

42. Wallis MD, Sarathy S, Bhatia SK, Massarotto P, Kosior E, Mercier A (2008) Catalytic degradation of high-density polyethylene in a reactive extruder. Ind Eng Chem Res 47:5175-5181

43. Na J-G, Jeong B-H, Chung SH, Kim S-S (2006) Pyrolysis of low-density polyethylene using synthetic catalysts produced from fly ash. J Mater Cycles Waste Manage 8:126-132
44. Vasile C, Brebu MA, Karayildirim T, Yanik J, Darie H (2007) Feedstock recycling from plastics and thermosets fractions of used computers. II. Pyrolysis oil upgrading. Fuel 86:477-485

45. Kaminsky W, Zorriqueta I-JN (2007) Catalytical and thermal pyrolysis of polyolefins. J Anal Appl Pyrolysis 79:368-374

46. Sekine Y, Fujimoto K (2003) Catalytic degradation of PP with an Fe/activated carbon catalyst. J Mater Cycles Waste Manage 5:107-112

47. Yanik J, Uddin MA, Sakata Y (2000) The effect of red mud on the liquefaction of waste plastics in heavy vacuum gas oil. Energy Fuels 15:163-169

48. Botas JA, Bravo M, Escola JM, García P (2006) Catalytic upgrading of higher 1-alkenes from polyethylene thermal cracking by modified Wacker oxidation. J Mater Cycles Waste Manage 8:122-125

49. Chiu S-J, Cheng W-H (2000) Promotional effect of copper(II) chloride on the thermal degradation of poly(ethylene terephthalate). J Anal Appl Pyrolysis 56:131-143

50. Obuchi E, Suyama M, Nakano K (2001) Decomposition of mixed plastics consisting of polypropylene and polyethylene terephthalate into oils over titania/silica catalysts. J Mater Cycles Waste Manage 3:88-92

51. Yoshioka T, Kitagawa E, Mizoguchi T, Okuwaki A (2004) High selective conversion of poly(ethylene terephthalate) into oil using $\mathrm{Ca}(\mathrm{OH})_{2}$. Chem Lett 33:282-283

52. Yoshioka T, Grause G, Otani S, Okuwaki A (2006) Selective production of benzene and naphthalene from poly(butylene terephthalate) and poly(ethylene naphthalene-2,6-dicarboxylate) by pyrolysis in the presence of calcium hydroxide. Polym Degrad Stab 91:1002-1009

53. Grause G, Matsumoto S, Kameda T, Yoshioka T (2011) Pyrolysis of mixed plastics in a fluidized bed of hard burnt lime. Ind Eng Chem Res 50:5459-5466

54. Grause G, Tsukada N, Hall WJ, Kameda T, Williams PT, Yoshioka T (2010) High-value products from the catalytic hydrolysis of polycarbonate waste. Polym J 42:438-442

55. Tsuji T, Tanaka Y, Itoh H (2001) Two-stage thermal gasification of polyolefins. J Mater Cycles Waste Manage 3:2-7

56. Tsuji T, Okajima S, Sasaki A, Masuda T (2005) Steam reforming of oils produced from waste plastics. J Chem Eng Jpn 38:859-864

57. Tsuji T, Hatayama A (2009) Gasification of waste plastics by steam reforming in a fluidized bed. $\mathrm{J}$ Mater Cycles Waste Manage 11:144-147

58. Tongamp W, Zhang Q, Saito F (2008) Hydrogen generation from polyethylene by milling and heating with $\mathrm{Ca}(\mathrm{OH}) 2$ and $\mathrm{Ni}(\mathrm{OH}) 2$. Int J Hydrogen Energy 33:4097-4103

59. Slapak MJP, van Kasteren JMN, Drinkenburg AAH (2000) Design of a process for steam gasification of PVC waste. Resour Conserv Recy 30:81-93

60. Yamamoto T, Isaka K, Sato H, Matsukura Y, Ishida H (2000) Gasification and smelting system using oxygen blowing for municipal waste. ISIJ Int 40:260-265

61. Kawamoto K, Mabuchi K (2001) Formation characteristics of polychlorinated dibenzo- $p$-dioxins, polychlorinated dibenzofurans, and coplanar PCBs in fly ash from a gasification-melting process of municipal solid waste. J Mater Cycles Waste Manage 3:38-47

62. Kamo T, Takaoka K, Otomo J, Takahashi H (2006) Production of hydrogen by steam gasification of dehydrochlorinated poly(vinyl chloride) or activated carbon in the presence of various alkali compounds. J Mater Cycles Waste Manage 8:109-115

63. Kamo T, Wu B, Egami Y, Yasuda H, Nakagome H (2011) Influence of mixed molten carbonate composition on hydrogen 
formation by steam gasification. J Mater Cycles Waste Manage 13:50-55

64. Yasuda H, Yamada O, Zhang A, Nakano K, Kaiho M (2004) Hydrogasification of coal and polyethylene mixture. Fuel 83:2251-2254

65. Choi Y-C, Lee J-G, Kim J-H, Park T-J (2007) High temperature air-blown gasification of Korean anthracite and plastic waste mixture. Korean J Chem Eng 24:706-710

66. van Kasteren JMN (2006) Co-gasification of wood and polyethylene with the aim of $\mathrm{CO}$ and $\mathrm{H}_{2}$ production. J Mater Cycles Waste Manage 8:95-98

67. Mun T-Y, Seon P-G, Kim J-S (2010) Production of a producer gas from woody waste via air gasification using activated carbon and a two-stage gasifier and characterization of tar. Fuel 89:3226-3234

68. Uemura Y, Baba K, Ohe H, Ohzuno Y, Hatate Y (2003) Catalytic decomposition of hydrocarbon into hydrogen and carbon in a spouted-bed reactor as the second-stage reactor of a plastic recycling process. J Mater Cycles Waste Manage 5:94-97

69. Song R, Jiang Z, Bi W, Cheng W, Lu J, Huang B, Tang T (2007) The combined catalytic action of solid acids with nickel for the transformation of polypropylene into carbon nanotubes by pyrolysis. Chem Eur J 13:3234-3240

70. Fukushima M, Wu B, Ibe H, Wakai K, Sugiyama E, Abe H, Kitagawa K, Tsuruga S, Shimura K, Ono E (2010) Study on dechlorination technology for municipal waste plastics containing polyvinyl chloride and polyethylene terephthalate. J Mater Cycles Waste Manage 12:108-122

71. Kakuta N, Shimizu A, Ohkita H, Mizushima T (2009) Dehydrochlorination behavior of polyvinyl chloride and utilization of carbon residue: effect of plasticizer and inorganic filler. J Mater Cycles Waste Manage 11:23-26

72. Uddin MA, Sakata Y, Shiraga Y, Muto A, Murata K (1999) Dechlorination of chlorine compounds in poly(vinyl chloride) mixed plastics derived oil by solid sorbents. Ind Eng Chem Res 38:1406-1410

73. Masuda Y, Uda T, Terakado O, Hirasawa M (2006) Pyrolysis study of poly(vinyl chloride)-metal oxide mixtures: quantitative product analysis and the chlorine fixing ability of metal oxides. J Anal Appl Pyrolysis 77:159-168

74. Bhaskar T, Matsui T, Kaneko J, Uddin MA, Muto A, Sakata Y (2002) Novel calcium based sorbent $(\mathrm{Ca}-\mathrm{C})$ for the dehalogenation $(\mathrm{Br}, \mathrm{Cl})$ process during halogenated mixed plastic $(\mathrm{PP} /$ $\mathrm{PE} / \mathrm{PS} / \mathrm{PVC}$ and HIPS-Br) pyrolysis. Green Chem 4:372-375

75. Bhaskar T, Kaneko J, Muto A, Sakata Y, Jakab E, Matsui T, Uddin MA (2004) Pyrolysis studies of PP/PE/PS/PVC/HIPS-Br plastics mixed with PET and dehalogenation $(\mathrm{Br}, \mathrm{Cl})$ of the liquid products. J Anal Appl Pyrolysis 72:27-33

76. Sakata Y, Bhaskar T, Uddin MA, Muto A, Matsui T (2003) Development of a catalytic dehalogenation $(\mathrm{Cl}, \mathrm{Br})$ process for municipal waste plastic-derived oil. J Mater Cycles Waste Manage 5:113-124

77. German K, Kulesza K, Florack M (2006) Influence of poly(bisphenol A carbonate) and poly(ethylene terephthalate) on poly(vinyl chloride) dehydrochlorination. J Mater Cycles Waste Manage 8:116-121

78. Saeki S, Kano J, Saito F, Shimme K, Masuda S, Inoue T (2001) Effect of additives on dechlorination of PVC by mechanochemical treatment. J Mater Cycles Waste Manage 3:20-23

79. Tongamp W, Kano J, Zhang Q, Saito F (2008) Mechanochemical dechlorination of polyvinyl chloride with calcium sulfates. J Mater Cycles Waste Manage 10:140-143

80. Mio H, Saeki S, Kano J, Saito F (2002) Estimation of mechanochemical dechlorination rate of poly(vinyl chloride). Environ Sci Technol 36:1344-1348
81. Endoh S, Takahashi K, Lee J-R, Ohya H (2006) Mechanical treatment of automobile shredder residue for its application as a fuel. J Mater Cycles Waste Manage 8:88-94

82. Shin S-M, Yoshioka T, Okuwaki A (1998) Dehydrochlorination behavior of rigid PVC pellet in $\mathrm{NaOH}$ solutions at elevated temperature. Polym Degrad Stab 61:349-353

83. Shin S-M, Yoshioka T, Okuwaki A (1998) Dehydrochlorination behavior of flexible PVC pellets in $\mathrm{NaOH}$ solutions at elevated temperature. J Appl Polym Sci 67:2171-2177

84. Yoshioka T, Kameda T, Imai S, Okuwaki A (2008) Dechlorination of poly(vinyl chloride) using $\mathrm{NaOH}$ in ethylene glycol under atmospheric pressure. Polym Degrad Stab 93:11381141

85. Wu Y-H, Zhou Q, Zhao T, Deng M-L, Zhang J, Wang Y-Z (2009) Poly(ethylene glycol) enhanced dehydrochlorination of poly(vinyl chloride). J Hazard Mater 163:1408-1411

86. Kameda T, Ono M, Grause G, Mizoguchi T, Yoshioka T (2009) Chemical modification of poly(vinyl chloride) by nucleophilic substitution. Polym Degrad Stab 94:107-112

87. Yoshihara M, Grause G, Kameda T, Yoshioka T (2010) Upgrading of poly(vinyl chloride) by chemical modifications using sodium sulfide. J Mater Cycles Waste Manage 12:264-270

88. Peng S, Chen L, Li L, Xie M, Huang H, Liu X (2010) Debromination of flame-retarded TV housing plastic waste. J Mater Cycles Waste Manage 12:103-107

89. Jakab E, Uddin MA, Bhaskar T, Sakata Y (2003) Thermal decomposition of flame-retarded high-impact polystyrene. J Anal Appl Pyrolysis 68-69:83-99

90. Bhaskar T, Hall WJ, Mitan NMM, Muto A, Williams PT, Sakata Y (2007) Controlled pyrolysis of polyethylene/polypropylene/ polystyrene mixed plastics with high impact polystyrene containing flame retardant: Effect of decabromo diphenylethane (DDE). Polym Degrad Stab 92:211-221

91. Mitan NMM, Brebu M, Bhaskar T, Muto A, Sakata Y (2007) Individual and simultaneous degradation of brominated high impact polystyrene and brominated acrylonitrile-butadienestyrene and removal of heteroelements $(\mathrm{Br}, \mathrm{N}$, and $\mathrm{O})$ from degradation oil by multiphase catalytic systems. J Mater Cycles Waste Manage 9:56-61

92. Brebu M, Sakata Y (2006) Novel debromination method for flame-retardant high impact polystyrene (HIPS-Br) by ammonia treatment. Green Chem 8:984-987

93. Luda MP, Balabanovich AI, Hornung A, Camino G (2003) Thermal degradation of a brominated bisphenol a derivative. Polym Adv Technol 14:741-748

94. Futamura S, Zhang A (2001) Carbon materials-catalyzed hydroliquefaction of flame-retardant plastics in organic solvents. J Mater Cycles Waste Manage 3:8-13

95. Goto M, Koyamoto H, Kodama A, Hirose T, Nagaoka S, McCoy BJ (2002) Degradation kinetics of polyethylene terephthalate in supercritical methanol. AlChE J 48:136-144

96. Genta M, Iwaya T, Sasaki M, Goto M, Hirose T (2005) Depolymerization mechanism of poly(ethylene terephthalate) in supercritical methanol. Ind Eng Chem Res 44:3894-3900

97. López-Fonseca R, Duque-Ingunza I, de Rivas B, Arnaiz S, Gutiérrez-Ortiz JI (2010) Chemical recycling of post-consumer PET wastes by glycolysis in the presence of metal salts. Polym Degrad Stab 95:1022-1028

98. Oku A, Hu LC, Yamada E (1997) Alkali decomposition of poly(ethylene terephthalate) with sodium hydroxide in nonaqueous ethylene glycol: a study on recycling of terephthalic acid and ethylene glycol. J Appl Polym Sci 63:595-601

99. Spychaj T, Fabrycy E, Spychaj S, Kacperski M (2001) Aminolysis and aminoglycolysis of waste poly(ethylene terephthalate). J Mater Cycles Waste Manage 3:24-31 
100. Mohd-Adnan A-F, Nishida H, Shirai Y (2008) Evaluation of kinetics parameters for poly(L-lactic acid) hydrolysis under high-pressure steam. Polym Degrad Stab 93:1053-1058

101. Iwaya T, Tokuno S, Sasaki M, Goto M, Shibata K (2008) Recycling of fiber reinforced plastics using depolymerization by solvothermal reaction with catalyst. J Mater Sci 43:2452-2456

102. Kamimura A, Akinari Y, Watanabe T, Yamada K, Tomonaga $F$ (2010) Efficient chemical recycling of waste fiber-reinforced plastics: use of reduced amounts of dimethylaminopyridine and activated charcoal for the purification of recovered monomer. J Mater Cycles Waste Manage 12:93-97

103. Kamimura A, Konno E, Yamamoto S, Watanabe T, Yamada K, Tomonaga F (2009) Formation of recycled plastics from depolymerized monomers derived from waste fiber-reinforced plastics. J Mater Cycles Waste Manage 11:38-41

104. Kamimura A, Yamada K, Kuratani T, Taguchi Y, Tomonaga F (2006) Effective depolymerization waste FRPs by treatment with DMAP and supercritical alcohol. Chem Lett 35:586-587

105. Yamada K, Tomonaga F, Kamimura A (2010) Improved preparation of recycled polymers in chemical recycling of fiberreinforced plastics and molding of test product using recycled polymers. J Mater Cycles Waste Manage 12:271-274

106. Hu L-C, Oku A, Yamada E (1998) Alkali-catalyzed methanolysis of polycarbonate. A study on recycling of bisphenol A and dimethyl carbonate. Polymer 39:3841-3845

107. Hidaka K, Iwakawa Y, Maoka T, Tanimoto F, Oku A (2009) Viable chemical recycling of poly(carbonate) as a phosgene equivalent illustrated by the coproduction of bisphenol $\mathrm{A}$ and carbohydrate carbonates. J Mater Cycles Waste Manage 11:6-10

108. Kim D, Kim B-k, Cho Y, Han M, Kim B-S (2008) Kinetics of polycarbonate glycolysis in ethylene glycol. Ind Eng Chem Res 48:685-691

109. Margon V, Agarwal US, Bailly C, de Wit G, van Kasteren JMN, Lemstra PJ (2006) Supercritical carbon dioxide assisted extraction from the polycarbonate depolymerization mixture. J Supercrit Fluid 38:44-50

110. Margon V, Agarwal US, Peters CJ, de Wit G, Bailly C, van Kasteren JMN, Lemstra PJ (2005) Phase equilibria of binary, ternary and quaternary systems for polymerization/depolymerization of polycarbonate. J Supercrit Fluid 34:309-321

111. Sato Y, Kondo Y, Tsujita K, Kawai N (2005) Degradation behaviour and recovery of bisphenol-A from epoxy resin and polycarbonate resin by liquid-phase chemical recycling. Polym Degrad Stab 89:317-326

112. Molero C, de Lucas A, Rodríguez JF (2006) Recovery of polyols from flexible polyurethane foam by "split-phase" glycolysis with new catalysts. Polym Degrad Stab 91:894-901

113. Molero C, de Lucas A, Rodríguez JF (2006) Recovery of polyols from flexible polyurethane foam by "split-phase" glycolysis: glycol influence. Polym Degrad Stab 91:221-228

114. Troev K, Grancharov G, Tsevi R, Tsekova A (2000) A novel approach to recycling of polyurethanes: chemical degradation of flexible polyurethane foams by triethyl phosphate. Polymer 41:7017-7022

115. Tagaya H, Suzuki Y-i, Komuro N, Kadokawa J-i (2001) Reactions of model compounds of phenol resin in sub- and supercritical water under an argon atmosphere. J Mater Cycles Waste Manage 3:32-37

116. Shibasaki Y, Kamimori T, Kadokawa J-i, Hatano B, Tagaya H (2004) Decomposition reactions of plastic model compounds in sub- and supercritical water. Polym Degrad Stab 83:481-485

117. Moriya T, Enomoto H (1999) Characteristics of polyethylene cracking in supercritical water compared to thermal cracking. Polym Degrad Stab 65:373-386

118. Aguado J, Serrano D, Vicente G, Sánchez N (2006) Effect of decalin solvent on the thermal degradation of HDPE. J Polym Environ 14:375-384
119. Chen J, Li Z, Jin L, Ni P, Liu G, He H, Zhang J, Dong J, Ruan R (2010) Catalytic hydrothermal depolymerization of nylon 6 . J Mater Cycles Waste Manage 12:321-325

120. Du A-K, Zhou Q, Wen Z-B, Yang J-W, van Kasteren JMN, Wang Y-Z (2011) Denitrogenation of acrylonitrile-butadienestyrene copolymers using polyethylene glycol/hydroxides. Polym Degrad Stab 96:870-874

121. Wahyudiono Kanetake T, Sasaki M, Goto M (2007) Decomposition of a Lignin Model Compound under Hydrothermal Conditions. Chem Eng Technol 30:1113-1122

122. Kamo T, Yufeng L, Akaishi N, Adachi M, Yasuda H, Nakagome $\mathrm{H}$ (2009) Liquefaction of printed circuit board by using waste biomass derived tar. In: The 5th symposium on feedstock and mechanical recycling of polymeric materials (ISFR2009). Chengdu (China), pp 186-192

123. Tanaka M, Takamizu A, Hoshino M, Sasaki M, Goto M (2011) Extraction of dietary fiber from Citrus junos peel with subcritical water. Food Bioprod Process (In Press)

124. Gondal MA, Siddiqui MN (2007) Identification of different kinds of plastics using laser-induced breakdown spectroscopy for waste management. J Environ Sci Heal A 42:1989-1997

125. Weiß M, Wüstenberg D, Momber AW (2003) Hydro-erosive separation of plastic fibers from textile compounds. J Mater Cycles Waste Manage 5:84-88

126. García M, Duque G, Gracia I, de Lucas A, Rodríguez J (2009) Recycling extruded polystyrene by dissolution with suitable solvents. J Mater Cycles Waste Manage 11:2-5

127. Furgiuele N, Lebovitz AH, Khait K, Torkelson JM (1999) Novel strategy for polymer blend compatibilization: solid-state shear pulverization. Macromolecules 33:225-228

128. Inagaki Y, Kiuchi S (2001) Converting waste polystyrene into a polymer flocculant for wastewater treatment. J Mater Cycles Waste Manage 3:14-19

129. Garcia D, Balart R, Crespo JE, Lopez J (2006) Mechanical properties of recycled PVC blends with styrenic polymers. J Appl Polym Sci 101:2464-2471

130. Zhang X, Lu C, Liang M (2009) Properties of natural rubber vulcanizates containing mechanochemically devulcanized ground tire rubber. J Polym Res 16:411-419

131. Zhu J, Zhang X, Liang M, Lu C (2011) Enhancement of processability and foamability of ground tire rubber powder and LDPE blends through solid state shear milling. J Polym Res 18:533-539

132. Silva Spinacé MA, De Paoli MA (2001) Characterization of poly(ethylene terephtalate) after multiple processing cycles. J Appl Polym Sci 80:20-25

133. Chong MH, Chun BC, Chung Y-C, Cho BG (2006) Fire-retardant plastic material from oyster-shell powder and recycled polyethylene. J Appl Polym Sci 99:1583-1589

134. Sridhar V, Xiu ZZ, Xu D, Lee SH, Kim JK, Kang DJ, Bang D-S (2009) Fly ash reinforced thermoplastic vulcanizates obtained from waste tire powder. Waste Manage (Oxford) 29:1058-1066

135. Buekens A, Sevenster A (2010) Vinyl 2010 - nearing the target date. J Mater Cycles Waste Manage 12:184-192

136. Buekens A, Cen K (2011) Waste incineration, PVC, and dioxins. J Mater Cycles Waste Manag 13:190-197

137. Cho S-J, Kim K-H, Jung H-Y, Kwon O-J, Seo Y-C (2010) Characteristics of products and PCDD/DF emissions from a pyrolysis process of urethane/styrofoam waste from electrical home appliances. J Mater Cycles Waste Manage 12:98-102

138. Tanaka M (2007) Waste management for a sustainable society. J Mater Cycles Waste Manage 9:2-6

139. Joung H-T, Cho S-J, Seo Y-C, Kim W-H (2007) Status of recycling end-of-life vehicles and efforts to reduce automobile shredder residues in Korea. J Mater Cycles Waste Manage 9:159-166 